\title{
Enzymatic Metabolism of Flavonoids by Gut Microbiota and Its Impact on Gastrointestinal Cancer
}

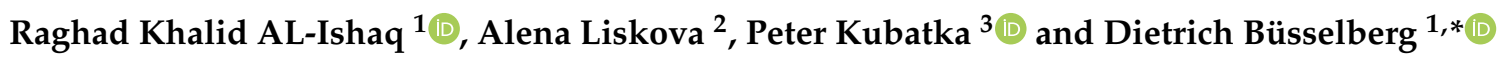 \\ 1 Weill Cornell Medicine-Qatar, Education City, Qatar Foundation, Doha 24144, Qatar; \\ rkmalishaq@hotmail.com \\ 2 Department of Obstetrics and Gynecology, Jessenius Faculty of Medicine, Comenius University in Bratislava, \\ 03601 Martin, Slovakia; esova5@uniba.sk \\ 3 Department of Medical Biology, Jessenius Faculty of Medicine, Comenius University in Bratislava, \\ 03601 Martin, Slovakia; peter.kubatka@uniba.sk \\ * Correspondence: dib2015@qatar-med.cornell.edu; Tel.: +974-4492-8334; Fax: +974-4492-8333
}

\section{check for}

updates

Citation: AL-Ishaq, R.K.; Liskova, A.; Kubatka, P.; Büsselberg, D. Enzymatic Metabolism of Flavonoids by Gut Microbiota and Its Impact on Gastrointestinal Cancer. Cancers 2021, 13, 3934. https://doi.org/10.3390/ cancers13163934

Received: 27 June 2021

Accepted: 2 August 2021

Published: 4 August 2021

Publisher's Note: MDPI stays neutral with regard to jurisdictional claims in published maps and institutional affiliations.

Copyright: (C) 2021 by the authors. Licensee MDPI, Basel, Switzerland. This article is an open access article distributed under the terms and conditions of the Creative Commons Attribution (CC BY) license (https:// creativecommons.org/licenses/by/ $4.0 /)$.
Simple Summary: Flavonoid's consumption is reported to impact GI cancer progression positively. As $90 \%$ of flavonoids consumed, undergo metabolism and conversion by the human gut microbiome, understanding their enzymatic bioconversion and metabolism could advance the current knowledge of their anticancer activities. While it is reported that specific flavonoids target cancer-related pathways such as apoptosis, inflammation and cellular proliferation, efforts are required to assess the possibility of combining those specific flavonoids together or with current treatment such as chemotherapy and evaluate their effect on the pathogenesis of GI cancer. Additionally, Studies aimed to standardize flavonoids administered concentration, purification and isolation methods are required.

Abstract: Gastrointestinal (GI) cancer is a prevalent global health disease with a massive burden on health care providers. Internal and external factors such as obesity, smoking, diet (red meat), low socioeconomic status and infection with Helicobacter pylori are the critical risk factors of GI cancers. Flavonoids are natural phenolic compounds found abundantly in fruits and vegetables. Upon ingestion, $90 \%$ of flavonoids consumed require further enzymatic metabolism by the gut microbiome to enhance their bioavailability and absorption. Several epidemiological studies reported that consumption of flavonoids and their enzymatic conversion by gut microbes is strongly associated with the reduced risk of GI cancer development. This review summarizes the current knowledge on the enzymatic conversion of flavonoids by the human gut microbiome. It also addresses the underlying anti-GI cancer effects on metabolic pathways such as apoptosis and cellular proliferation. Overall, metabolites produced from flavonoid's enzymatic conversion illustrate anti-GI cancer effects, but the mechanisms of action need further clarification.

Keywords: gastrointestinal cancer; flavonoids; gut enzymes; microbiome; anticancer

\section{Introduction}

\subsection{Gastrointestinal Cancer}

Cancers are one of the major causes of disabilities and death worldwide [1]. It is a heterogeneous disease triggered by the impairment of cellular function and homeostasis [2] Among all organ cancers, gastrointestinal (GI) cancers account for many malignancies and are considered a challenging public health problem with a substantial medical and economic burden worldwide [3]. "GI cancers" is a term used to describe cancers that affect the digestive system, including colorectal cancer (CRC), gastric cancer (GC), esophageal cancer (EC), hepatocellular carcinoma (HCC) and pancreatic cancer (PC) [4]. Factors such as obesity, smoking, diet (red meat), low socioeconomic status and infection with Helicobacter pylori are the critical risk factors of GI cancers [5]. Depending on the type of cancer, 
symptoms and signs include fatigue, weight loss, abdominal pain, anorexia, dysphagia and hematemesis [6,7]. Cancer progression in the body results from the loss of apoptotic functions and the uncontrolled cell growth and differentiation leading to neoplastic cell expansion [8]. Critical pathways involved in GI cancer biology include intrinsic and extrinsic apoptotic pathways, protein kinase B (AKT) and phosphatidylinositol 3-kinase (PI3K), which plays a role in cellular proliferation, nuclear factor kappa (NF- $\kappa \mathrm{B})$, that plays a role in the progression of cancer by triggering cellular inflammation, and epithelial-mesenchymal transition (EMT) which promote cellular invasion and metastasis [9]. More efforts are needed to understand the underlying causes of these pathways on the progression of GI cancer.

\subsection{Flavonoids and Cancer}

Flavonoids are natural products ubiquitously found in fruits and vegetables [10]. They are biologically active secondary plant metabolites with multiple health benefits [11]. Structurally, flavonoids consist of 15 carbon atoms and two benzene rings (A and B) linked by an oxygenated heterocyclic $C$ ring. Depending on the structure of the $C$ ring, the functional group on the ring, and the attachment site to the $\mathrm{C}$ ring, flavonoids could be further classified into six subclasses: flavonols; flavones; flavanones; iso-flavones; flavan3-ols; and anthocyanosides, where each class differs in the degree of substitution and hydroxylation [12].

Recent epidemiological studies reported that regular consumption of flavonoids is strongly associated with the reduced risk of GI cancer development [13]. Another study reported an inverse association between the total intake of flavonoids and gastric adenocarcinoma [14]. As for colon cancer, a meta-analysis review was performed on 17 epidemiological studies to assess the impact of soy isoflavone consumption on colorectal cancer [15]. The results showed that soy isoflavone consumption reduced the risk of colorectal cancer by $23 \%$, with a relative risk value of 0.77 . Among the 17 reviewed studies, three studies used tofu as an exposure, two used soybeans, two used bean curd, four used soy products, one used genistein and five used a combination of soy products and isoflavone. In addition, results from an in vitro study demonstrated the ability of flavonoids to inhibit the growth of colon cancer cells [16]. Additionally, an inverse association between colon cancer and flavonoid intake (anthocyanidins, flavanones and flavones) was observed in a case-control study performed on the Chinese population (3264 participants) [17]. More studies are required to explain the association observed and address the possible protective effect of flavonoids on GI cancer.

\subsection{Flavonoids Metabolism in the Gut}

Dietary flavonoids exist either as aglycones with no attached sugars or glycosides with attached sugars (most common) [18]. Depending on the type of the attached sugar moiety, extensive metabolism by gut microbiota and host tissue occurs [19]. Global interest in flavonoids products produced by intestinal microbiota and their potential physiological role has recently increased [20]. After ingestion, approximately $10 \%$ of flavonoids glycosides are absorbed in the upper GI tract, where the remaining $90 \%$ pass through the small intestine to reach the colon as non- metabolized and non-absorbed flavonoids [21] (Figure 1). Unabsorbed flavonoids undergo enzymatic modification in the small intestine, such as oxidation, reduction and decarboxylation, as a preparation step before colon entry. Once in the colon, colonic enzymes produced by microbiota eliminate glycosides to produce flavonoid aglycones, which are further metabolized into ring fission products [22]. It is proposed that these catabolites produced with lower molecular weight reflect the physiological effect of their flavonoid parent compounds [23]. In the liver, further conjugation of metabolites occurs to produce sulfate derivatives, excreted through bile and urine [24]. 


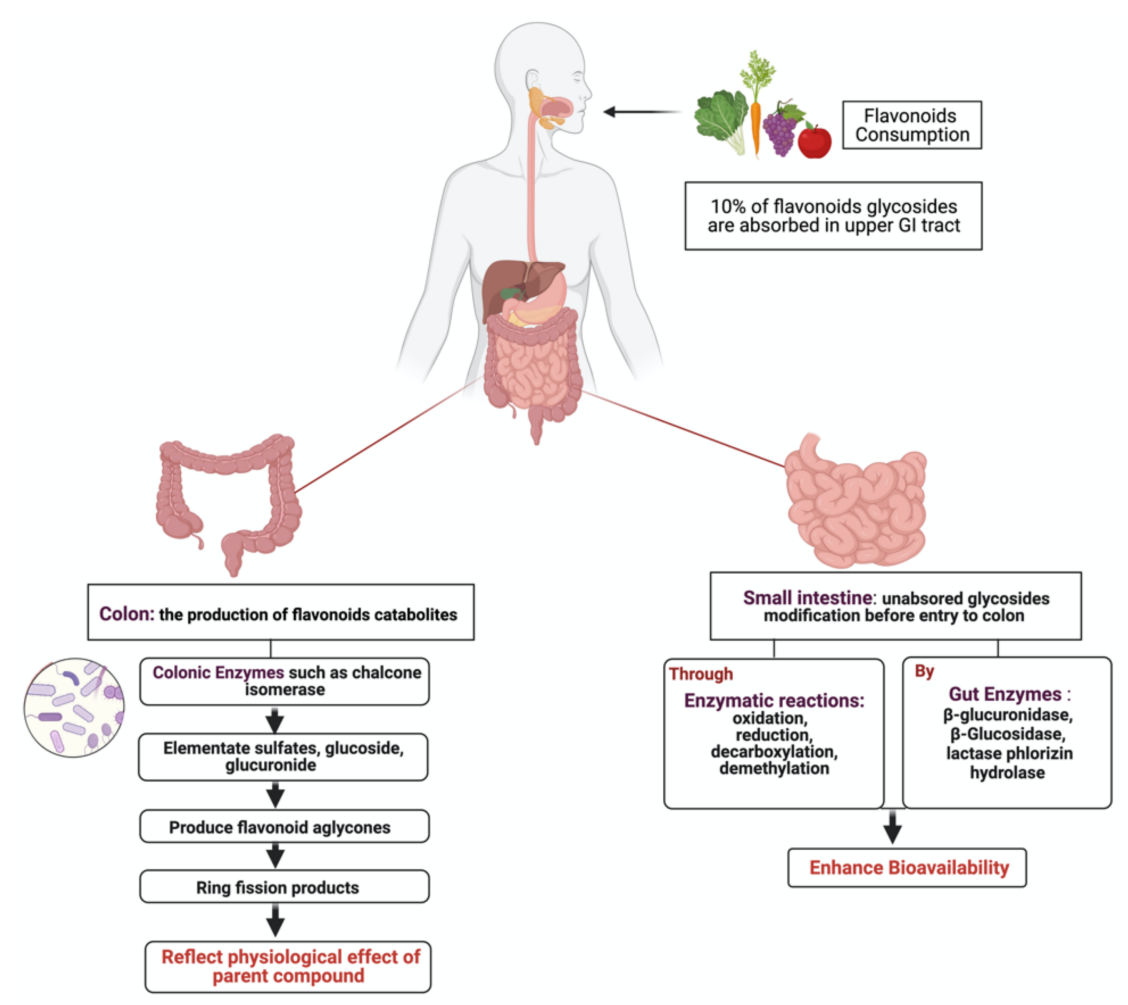

Figure 1. Illustration of flavonoids metabolism by gut microbiota. After the ingestion of flavonoid, a small percentage becomes absorbed in the upper GI tract, while the rest enters the colon for further modification to produce ring fission products that reflect the physiological effects of the parents' compound. Created with BioRender.com (accessed on 3 August 2021).

In the intestinal tract, several bacteria are capable of degrading and metabolizing flavonoids. Eubacterium ramulus, isolated from fecal samples, degrade various flavonoids in vitro enzymatically [25]. A study on 28 healthy participants investigated the impact of selected flavonoids (quercetin and rutin) on the flavonoid degrading bacterium, E. ramulus. The participants were given a rich flavonoid diet, and their fecal samples were collected. $E$. ramulus was detected in the fecal samples of all participants with a concentration ranging from $2.3 \times 10^{8}$ to $1.55 \times 10^{9}$ cells. $\mathrm{g}^{-1} \mathrm{dm}$. These results suggest that the administered dietary flavonoids could act as a substrate for E. ramulus resulting in the formation of flavonoid degradational products [26]. More studies are required to investigate the relationship between E. ramulus and other flavonoid groups (as the study investigated only quercetin and rutin) and classify other microbial species (Figure 2).

This review evaluates and summarizes studies that report flavonoids metabolism by gut microbiota enzymes and addresses their impact on the development of GI cancer pathways. Additionally, gaps in the current literature were identified. 


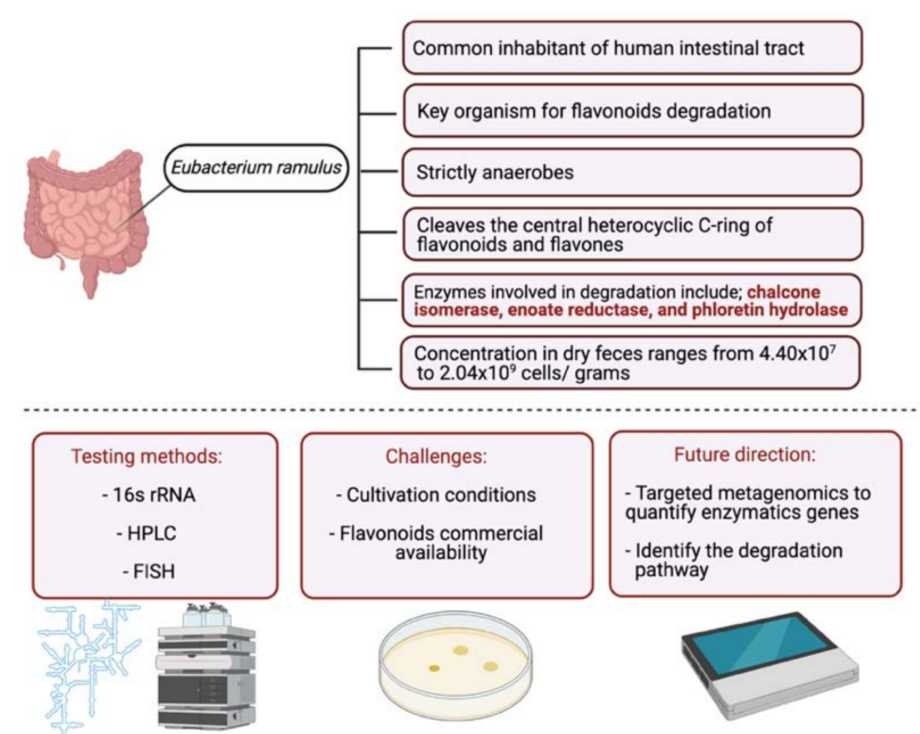

Figure 2. Schematic illustration of E. ramulus, a flavonoid degrading bacterium. The figure is divided into two parts. In the upper part, information about the bacteria is stated, and in the lower part, common testing methods, challenges with studying bacteria and efforts required to improve the field are listed. Created with BioRender.com (accessed on 3 August 2021).

\section{Search Strategy and Selection Criteria}

A comprehensive search on databases such as Medline, PubMed and Scopus was carried out for studies published from 2000 using the search terms "flavonoids", "microbiota", "flavonoids AND microbiota", "flavonoids metabolism", "flavonoids ring fission", "flavonoids AND GI cancer", "gut microbiota enzymes for flavonoids", "flavonoids OR flavonoids subclasses AND GI cancer", "flavonoids subclasses AND gastric cancer" and "flavonoids subclasses AND colorectal cancer". The search yielded 2338 articles, and in this article, we selected 182 articles and analyzed them in detail. Eligible studies included in this review are in vivo, in vitro and clinical trials papers addressing flavonoids metabolism by human gut microbiota and the possible underlying anti-GI cancer effects. Duplicates and studies with other flavonoid metabolism mechanisms were excluded.

\section{Metabolism of Flavonoids by Gut Microbiota}

As discussed in Section 1.3, flavonoids require further modification and transformation by the gut microbiota to enhance their bioavailability and biological activities. The regulation of specific reactions catalyzed by bacterial enzymes of gut microbiota may offer new clinical opportunities to enhance the efficacy of numerous drugs, including flavonoidderived substances [27]. Scientific databases demonstrate comprehensive results on the biological activities of flavonoids metabolites generated by phase I and phase II metabolic processes linked with gut microbiota-mediated biotransformations [28]. In this section, flavonoids will be divided into their respective groups to discuss common microorganisms, chemical reactions involved in the transformation, the impact of the metabolism of biological properties of the flavonoids. Table 1 summarizes the main findings in the literature. 
Table 1. Representative Flavonoids and their Underlying Metabolism by Gut microbiota.

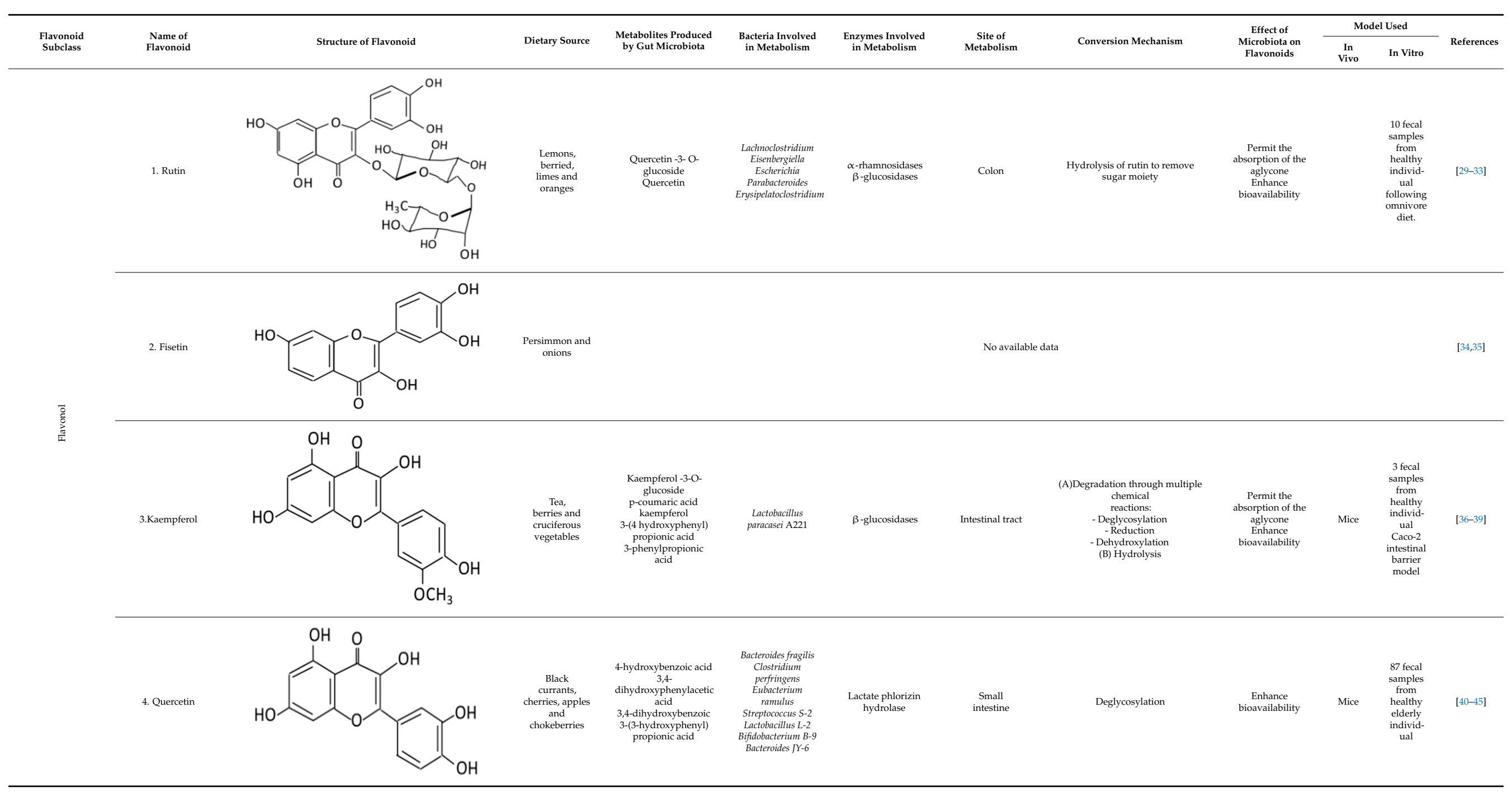


Table 1. Cont

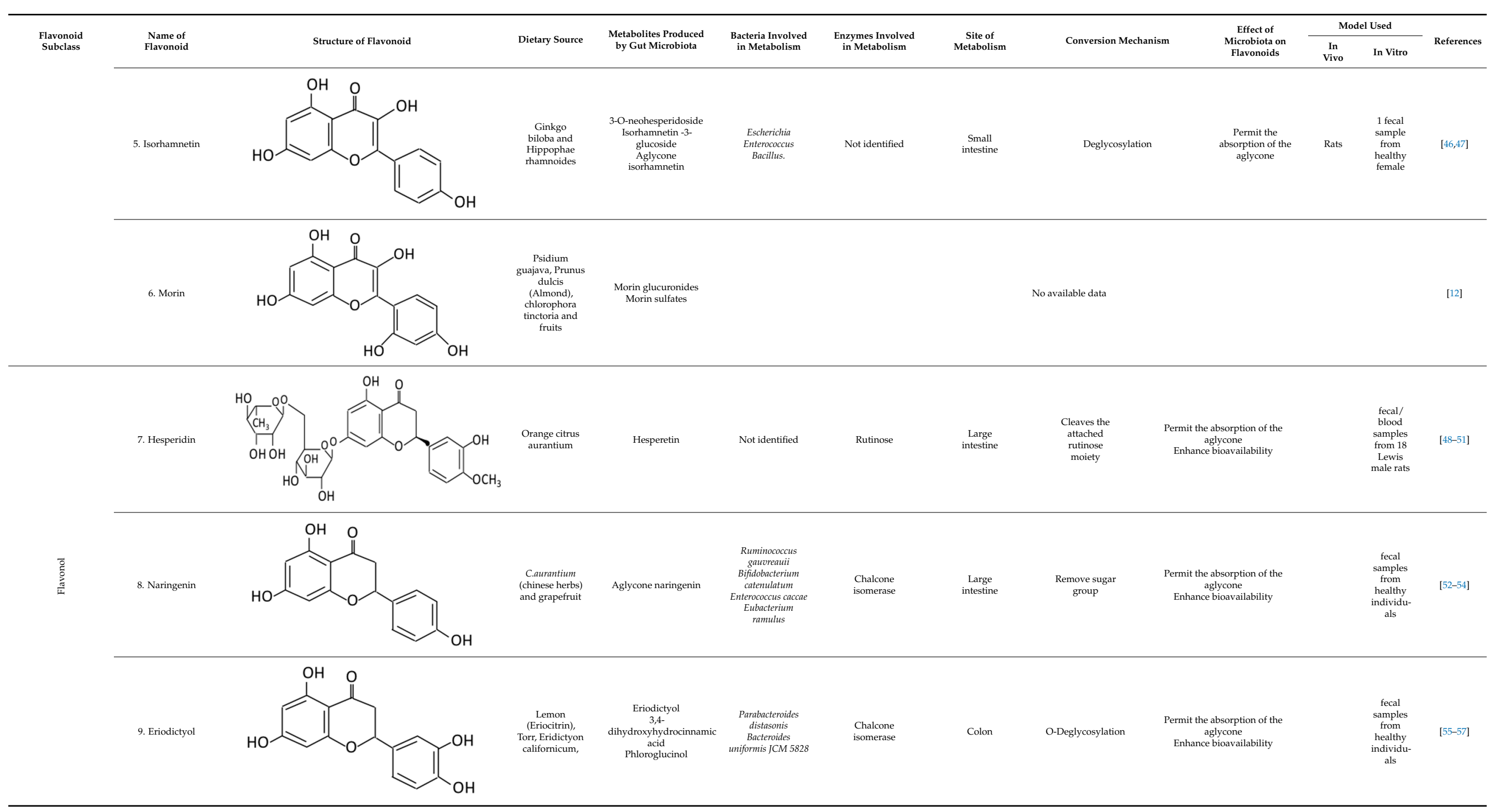


Table 1. Cont.

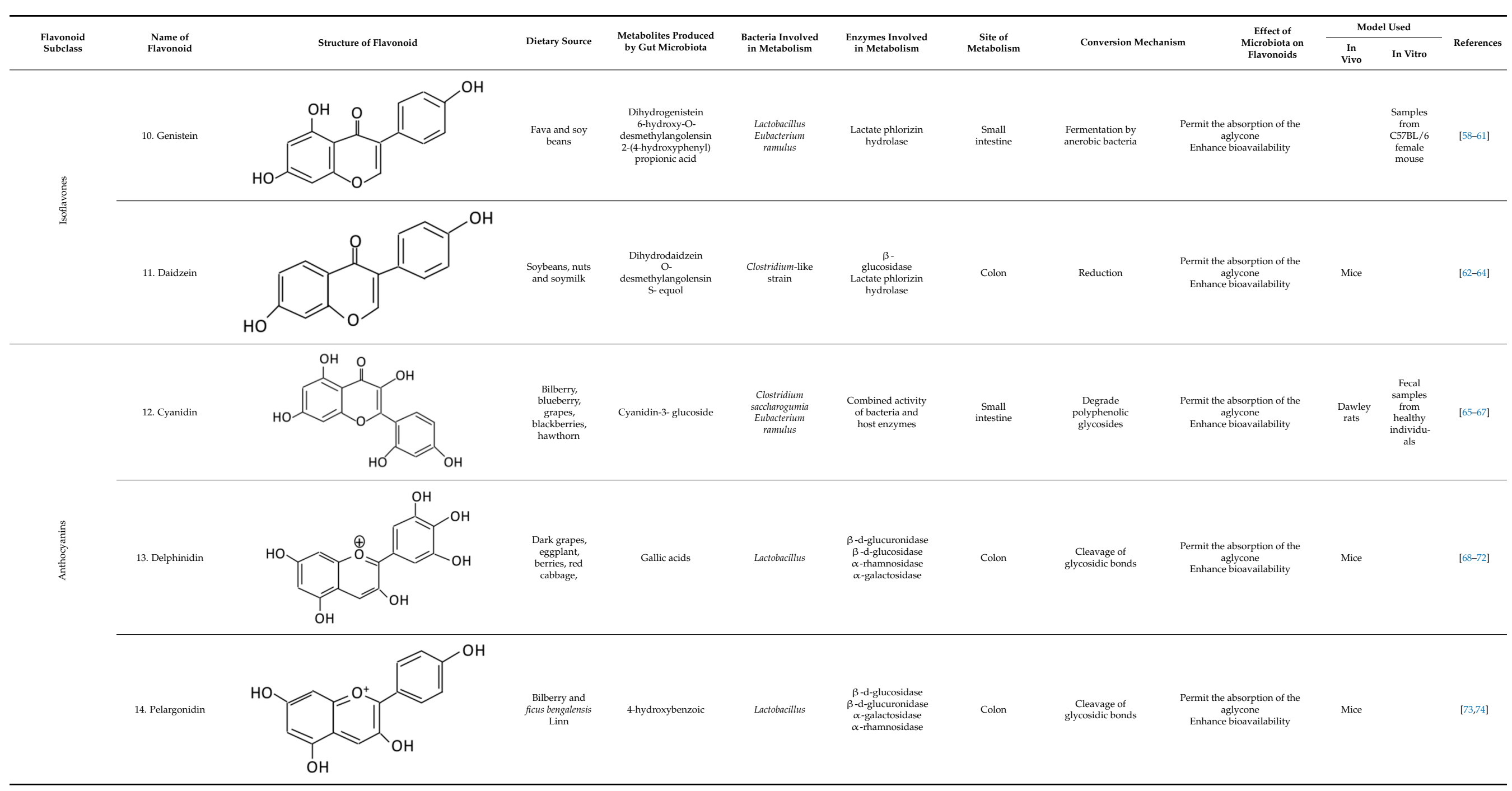


Table 1. Cont

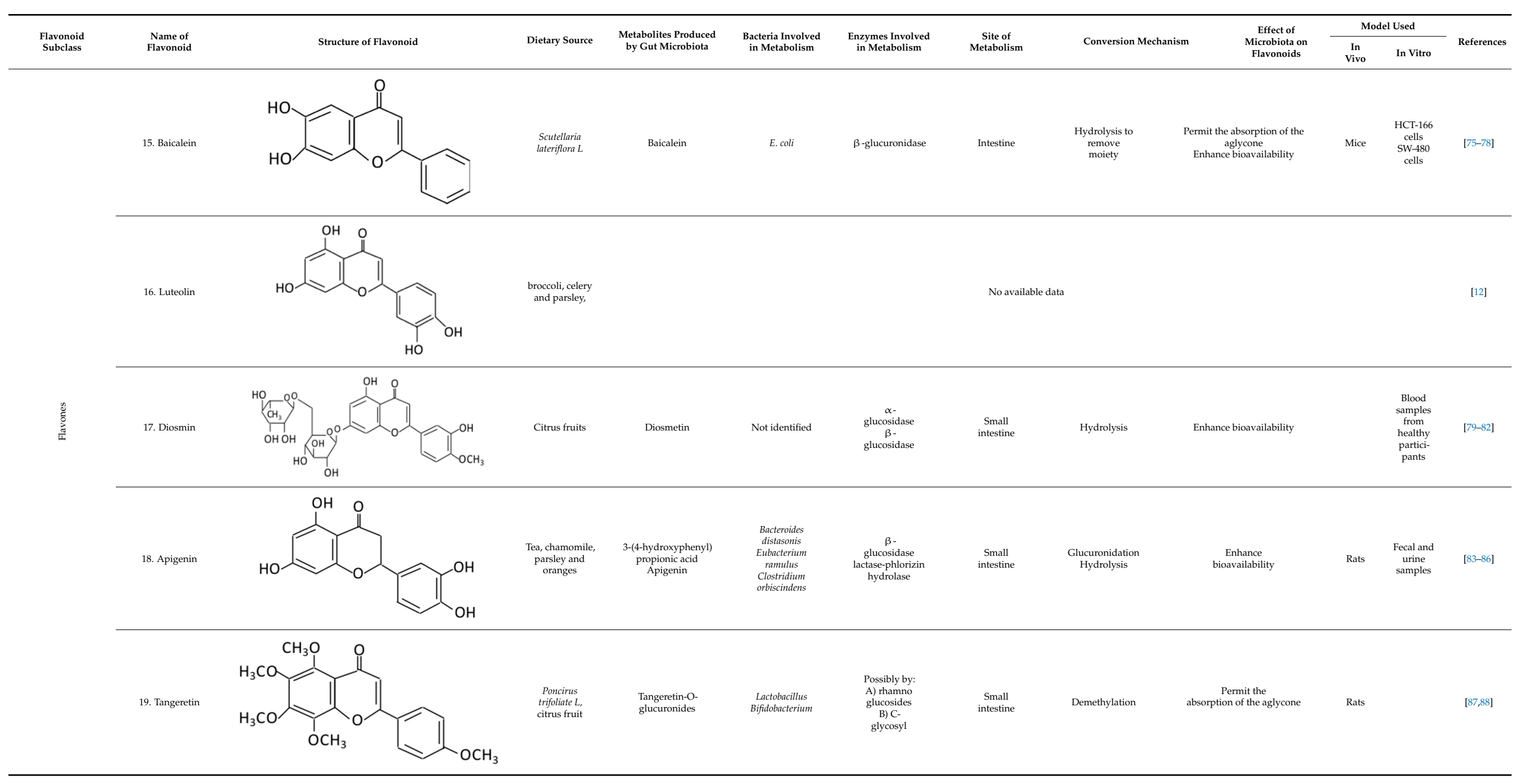


Table 1. Cont

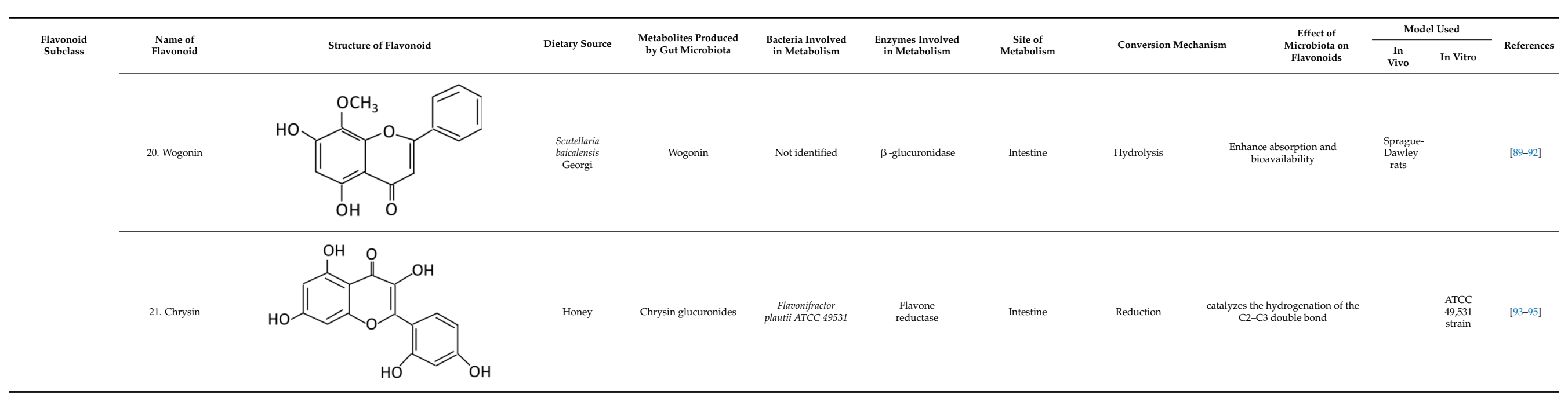




\subsection{Flavonol}

Flavonols constitute a significant class of flavonoids and are divided into six groups. The unsaturated carbon ring at $\mathrm{C} 2-\mathrm{C} 3$ characterizes them. They are most prevalent in grapes, lettuce, kale, onions and barriers [96].

\subsubsection{Rutin}

Rutin is a glycoconjugate form of quercetin, representing the most consumed flavonol in the United Kingdom and Europe (3.75\%) [29]. Rutin exerts multiple health benefits as it has antioxidant and anti-neurodegenerative properties [30]. In the upper intestinal tract, rutin is poorly absorbed, and it accumulates in the large intestine. Several gut microbes such as Lactobacillus acidophilus, Lactobacillus plantarum and Bifidobacterium dentium possess alpha-rhamnosidase activities in the colon which hydrolyzes rutin, removing sugar moiety and permitting aglycone absorption [31]. A study investigated the metabolism of rutin by the human gut microbiota using anaerobic incubations of freshly collected stool samples from 10 healthy participants [32]. Products from rutin conversion (quercetin-3-glucoside and quercetin) were detected in all samples with drastic variation in the concentration, suggesting inter-individual variation in capability or preference for the metabolism of rutin. Additionally, Enterobacteriaceae were associated with quercetin-3-glucoside production, while Lachnospiraceae with quercetin production from rutin metabolism. In addition, the study reported that the alpha diversity in the active subset of the microbial community is low compared to the whole community, which suggests that part of the microbial community is metabolically activated by rutin.

Differential proteomics was used to investigate the impact of rutin on Lactobacillus acidophilus biological activities [33]. It regulated the level of protein expression involved in the stress response mechanism.

More efforts are required to investigate the role of gut metabolism in the bioavailability and absorption of rutin and the possible bacteria-polyphenols interaction activities.

\subsubsection{Fisetin}

Fisetin is a bioactive flavonol with chemoprotective and anti-inflammatory properties [34]. The metabolism and bioconversion of fisetin by gut microbiota are poorly discussed in the literature. A study published in 2013 investigated the interaction of multiple flavonoids, including fisetin and probiotic bacteria [35], showed that flavonoids could promote the expression of nitric oxide produced by Bifidobacterium adolescentis suggesting that flavonoids may have a prebiotic-like effect on the activities of B. adolescentis.

\subsubsection{Kaempferol}

A nontoxic dietary flavonol possesses antioxidant, anti-inflammatory, anti-microbial and anticancer abilities [36]. In the intestinal tract, kaempferol undergoes degradation reactions by gut microbiota to produce absorbable metabolites [37]. Variations in concentration and duration required to produce these metabolites were observed in a study that measured the interaction of phenolic compounds with gut microbiota using fecal samples from healthy participants [38]. Additionally, a study investigated the effects of Lactobacillus paracasei A221 on the bioavailability and functionality of kaempferol glycoside [39], showing that treatment of Lactobacillus paracasei A221 on the intestinal barrier model improved barrier integrity. In addition, the direct bioconversion of kaempferol by this strain seems to enhance the beneficial health properties of kaempferol metabolites, suggesting that Lactobacillus paracasei A221 is capable of modulating and enhancing the bioavailability and functionality of kaempferol.

\subsubsection{Quercetin}

Quercetin is an antioxidant flavonol with critical biological activities on cellular transduction and progression pathways regulation [40]. It presents mainly as a glycoside (conjugated to sugar moieties) rather than an aglycone, which reduces its bioavailabil- 
ity [41]. After ingestion, quercetin reaches the small intestine to undergo deglycosylation by Lactate phlorizin hydrolase enzyme, yielding quercetin aglycone [42]. It is metabolized by multiple gut microbes such as Bacteroides fragilis, Clostridium perfringens, Eubacterium ramulus, Streptococcus S-2 Lactobacillus L-2, Bifidobacterium B-9 and Bacteroides JY-6 to produce 3,4-dihydroxyphenylacetic acid, 3-(3-hydroxyphenyl) propionic acid, 3,4-dihydroxybenzoic and 4-hydroxybenzoic acid metabolites [43,44]. Some of these metabolites have biological activities such as free radical scavenging activities observed with 4-hydroxybenzoic acid administration [44]. Concentration, abundance and positive relationship between gut microbes and quercetin metabolism vary depending on food intake, as reported in a study performed on elderly Japanese participants [45].

\subsubsection{Isorhamnetin}

This is a flavonol is found abundantly in medical plants and has anti-obesity, anticancer and anti-diabetic activities [46]. To understand isorhamnetin's metabolic pathway and metabolites, fecal samples from a healthy female participant and isolated different bacterial colonies were collected [47]. Using ultra-performance liquid chromatography technique coupled with the MetabolynxTM software, the metabolic profile of the samples was analyzed. In this case, 100 bacterial colonies were identified (68 Escherichia, 16 Enterococcus and 16 Bacillus). These bacterial colonies were incubated anaerobically with isorhamnetin-3-O-neohesperidoside to measure metabolites production. Four metabolites were observed: isorhamnetin-3-Oneohesperidoside (M1), isorhamnetin-3-O-glucoside (M2), isorhamnetin (M3) and quercetin (M4). The study suggested the metabolic pathway to be as follows; deglycosylation occurs first to produce isorhamnetin-3-O-glucoside and subsequently produce isorhamnetin, then demethylation occurs to produce quercetin. Additional studies are required to support these findings and to highlight important enzymes involved in the mechanism.

\subsection{Flavanones}

Flavanones are known as dihydroxyflavones and are recognized by the saturated and oxidized $\mathrm{C}$ ring. They are found abundantly in citrus fruits with the ability to scavenge free radicals [97].

\subsubsection{Hesperidin}

Hesperidin is a major flavanone composed of hesperetin (aglycone) conjugated by rutinose [48]. Hesperidin is considered a potential anticancer, antioxidant, anti-depressive and immunomodulatory agent [49]. In the small intestine, hesperidin is poorly absorbed, and it is highly dependent on the conversion by the gut microbiome. Gut microbes in the large intestine cleave the attached rutinose moiety, forming hesperetin, enhancing bioavailability [50]. To investigate the impact of oral administration of hesperidin on gut microbiota composition, 100-200 mg of hesperidin was administered orally to Lewis rats for four weeks [51]. The administration of hesperidin resulted in a higher Lactobacillus proportion. The reported changes in the small intestine were associated with a concentration decline in monocyte chemotactic protein 1 , supporting the prebiotic role of hesperidin.

\subsubsection{Naringenin}

A natural 2,3-dihydroflavonoid, present in citrus fruits, was reported to pose multiple bioactive benefits [52]. Orally administered naringenin has a low bioavailability. Under the metabolism mediated by gut microbes, naringenin could be a precursor to several metabolites with physiological effects [53]. The effects of naringenin on commensal bacteria's growth and genetic expressions such as Ruminococcus gauvreauii, Bifidobacterium catenulatum and Enterococcus caccae were measured using single-molecule RNA sequencing [54]. Tested bacteria responded differently to treatments of naringenin. While the upregulated genes of Ruminococcus gauvreauii are critical in iron uptake, the Bifidobacterium catenulatum genes are important in cellular metabolism and DNA repair. Enterococcus caccae downreg- 
ulated genes responsible for sugar transport and upregulated transcription and protein transport pathways.

\subsubsection{Eriodictyol}

Eriodictyol is a flavonoid present in many medicinal plants and has significant health properties [55]. Hydrolysis of eriocitrin; an antioxidant present in lemon fruits, results in the formation of eriodictyol (aglycone). Microbes involved in the bioconversion reaction in the gut include Bacteroides distasonis and Bacteroides uniformis through a O-Deglycosylation reaction [56]. Additionally, Clostridium butyricum further metabolize eriodictyol to 3,4dihydroxyhydrocinnamic acid and Phloroglucinol, which poses antioxidant activities [57].

\subsection{Isoflavones}

Isoflavones are primarily found in soybeans and legumes. Isoflavones are further divided into genistein and daidzein [98]. They are known for their anticancer and DNA photoprotective effects [99].

\subsubsection{Genistein}

Genistein is a phytosterol found abundantly in soybeans. The metabolism of genistein by gut microbiota plays a crucial role in its bioavailability and bioactivity [58]. Multiple metabolites produced by genistein bioconversion are reported, but the pathway and mechanism remain unclear. An anaerobic bacterium identified as a member of Coriobacteriaceae reduces the activated double bond of genistein yielding in dihydrogenistein [59]. Additionally, E. ramulus cleaves the $\mathrm{C}$ ring and degrades genistein, producing $6^{\prime}-\mathrm{OH}-\mathrm{O}-$ desmethylangolensin $[60,61]$. More efforts are required to identify the metabolic pathways and gut enzymes involved in its bioconversion.

\subsubsection{Daidzein}

Daidzein, is a dietary phytoestrogen abundantly found in soybeans. Structurally, it is similar to genistein, but it lacks a hydroxyl group on the fifth position. [62]. To permit the absorption of daidzein through the gut epithelium, $\beta$-glucosidase cleaves and releases sugar moiety producing the aglycone [63]. The metabolic pathway of daidzein begins with a reduction reaction yielding dihydrodaidzein through the hydrogenation of the activated double bonds, followed by O-desmethylangolensin or S- equol production depending on gut microbes. Gut bacteria involved include the Clostridium-like strain and E. ramulus [64].

\subsection{Anthocyanins}

Anthocyanins are characterized as unoxidized, unsaturated, water-soluble flavonoids found abundantly in fruits and flowers, responsible for their coloration [100]. Anthocyanins exert several health benefits such as inhibiting mutagenesis, diminishing lipid peroxidation and reducing DNA damage [101].

\subsubsection{Cyanidin}

This flavonoid is found abundantly in crops and fruits, where it is usually conjugated to sugar [65]. Due to its low bioavailability, a substantial proportion of cyanidin ingested enters the large intestine, where it is metabolized by gut microbes [66]. Cyanidin-3- glucoside, is a metabolite degraded by gut microbes and investigated in rats [67]. Intestinal bacterial species E. ramulus and Clostridium saccharogumia convert cyanidin-3-glucoside to 2,4,6-trihydroxybenzoic acid and 2,4-dihydroxybenzoic acid via cyanidin. Cyanidin3-glucoside metabolism was also conducted in the absence of bacterial strains, but the products were low in concentration, suggesting that bacterial conversion is critical to support the proposed beneficial effects of cyanidin-3-glucoside. 


\subsubsection{Delphinidin}

Delphinidin is an anthocyanin found profusely in berries, red cabbage, grapes and sweet potatoes [68]. Delphinidin poses anti-inflammatory, antioxidant, anti-mutagenic and anti-turmeric properties [69]. Microbial catabolism of delphinidin to gallic acid and delphinidin-3-glucoside is required to enhance bioavailability. To produce these bioactive metabolites, gut microbes such as Lactobacillus breaks the glycosidic linkage using intestinal gut enzymes such as $\beta$-d-glucosidase, $\beta$-d-glucuronidase, $\alpha$-galactosidase and $\alpha$-rhamnosidase $[70,71]$. Additionally, using a cyclodextrin encapsulation to enhance the stability of delphinidin, improved bioavailability, allowing their release in the colon where they are metabolized and exert their potential health benefits [72].

\subsubsection{Pelargonidin}

It is a flavonoid found in blueberries and other berries. It displays cytotoxic effects [73] Similar to other anthocyanins, pelargonidin requires microbial metabolism to enhance bioavailability and bioactivity. Lactobacillus in the colon metabolizes pelargonidin, yielding in 4-hydroxybenzoic (the absorbable form). Enzymes involved in the metabolism include $\beta$-d-glucosidase, $\beta$-d-glucuronidase, $\alpha$-galactosidase and $\alpha$-rhamnosidase [70]. All anthocyanins, including pelargonidin, modulate microbiota's composition, increasing the concentration of probiotic bacteria by producing short-chain fatty acids (SCFA) [74].

\subsection{Flavones}

Flavones are widely distributed in flowers, fruits and leaves [102]. Flavones have a ketonic group at $\mathrm{C} 4$, an unsaturated $\mathrm{C}$ ring on the $\mathrm{C} 2-\mathrm{C} 3$, and lack hydroxylation on C3 [103].

\subsubsection{Baicalein}

It is an aglycone present in the roots of S. baicalensis, with anti-neurodegenerative, anti-inflammatory and anti-cardiovascular activities [75,76]. In the intestine, baicalin is metabolized by $\beta$-glucuronidase produced by E. coli, yielding baicalein, thus enhancing absorption, bioavailability and bioactivity [77]. Baicalein (aglycone) poses significant antiproliferative effects on human colon cancer cells compared to baicalin, supporting the key role of gut microbe's bioconversion [78].

\subsubsection{Diosmin}

A flavonoid commonly found in Citrus spp. It exerts a wide range of biological activities [79]. It was reported that the administration of diosmin in rats with gastric cancer resulted in the reduction of tumor rate, the suppression of inflammatory cytokines (IL-6, TNF-a and NF-KB), and the improvement of body weight [80]. Similar to other flavonoids, diosmin is poorly soluble, affecting its bioavailability. Following oral consumption, diosmin is hydrolyzed in the intestine by microbial enzymes such as $\alpha$-glucosidase and $\beta$-glucosidase into its aglycone, diosmetin [81]. Bioconversion of diosmin enhances bioavailability when measured in plasma samples from healthy participants [82]. More studies are required to identify the species involved in their bioconversion.

\subsubsection{Apigenin}

Apigenin is a phytoestrogen aglycone found abundantly in oranges, garlic, spinach, parsley and carrots [83]. The gastrointestinal tract plays a key role in the conjugation and metabolism of apigenin before entering the bloodstream [84]. Once in the colon, apigenin becomes the substrate for gut microbes that will aid in its degradation. Bacterial species capable of degrading apigenin include Bacteroides distasonis, Eubacterium ramulus and Clostridium orbiscindens yielding critical metabolites such as 3-(4-hydroxyphenyl) propionic acid [85]. 3-(4-hydroxyphenyl) propionic acid is beneficial during infection with influenzas triggering interferon type 1 pathway and preventing inflammation [86]. 


\subsubsection{Tangeretin}

A flavonoid abundantly found in the citrus peel of tangerine and in citrus fruits with a reported impact on the human gut microbiome composition [87]. The administration of polymethoxyflavones (PMFs) composed of nobiletin, tangeretin and 5-demethylnobiletin as main components, significantly increased the richness of the microbial community, but not the diversity, suggesting a possible interaction between PMFs and gut microbiota [88]. Lactobacillus and Bifidobacterium, two important probiotics, significantly increased after oral administration of PMFs, indicating their beneficial health effects. Metabolism of PMFs metabolites was carried out by demethylation, hydroxylation, demethoxylation and glucuronidation in the GI tract of the mice.

\subsubsection{Wogonin}

Wogonin is extracted from Scutellaria baicalensis roots and has been used as a traditional medicine as it poses both anti-bacterial and anti-viral activities [89,90]. Intestinal bacteria enzymes such as $\beta$-glucuronidase play a key role in the hydrolysis of wogonoside to its aglycone form, wogonin, facilitating its absorption and enhancing bioavailability [91]. Antibiotics administration significantly affects the plasma concentration of wogonin as observed in pseudogerm free and normal rats, suggesting that pharmacokinetics and pharmacological effects of wogonin depend heavily on the status of intestinal microbiota [92].

\subsubsection{Chrysin}

Chrysin is an apigenin analog and is found abundantly in honey and Thai propolis [93]. After ingestion, rapid metabolism of chrysin and excretion occurs, affecting its bioavailability and rendering its beneficial effects. In the intestine, enzymes such as flavone reductase reduce chrysin to its glucuronidase and improving absorption and bioavailability [94]. Metagenomic analysis of gut microbes confirmed that flr-like genes are broadly distributed in the human gut microbiome [95]. More evidence is required to exclude the possibility of horizontal gene transfer in the observed gene prevalence.

\section{Effects of Flavonoids on Gastrointestinal Cancer}

The positive impact of flavonoids consumption on breast and colorectal cancer was described in our previous publications, supporting the potential role of flavonoids on GI cancer [2,104-106]. To evaluate this further, we looked up the effects of flavonoids on general pathways impaired by GI cancers, such as apoptosis, cellular proliferation, inflammation and invasion (Section 4.1). Additionally, we addressed the potential impact on impaired specific pathways such as P53 translocation, extracellular Signal-Regulated Kinase and integrin (Section 4.2). Table 2 summarizes the main findings reported in the literature. 
Table 2. Representative Flavonoids and their Underlying Anticancer Effects.

\begin{tabular}{|c|c|c|c|c|c|c|c|c|c|}
\hline \multirow{2}{*}{ Flavonoid Subclass } & \multirow{2}{*}{$\begin{array}{l}\text { Name of } \\
\text { Flavonoid }\end{array}$} & \multirow{2}{*}{$\begin{array}{l}\text { Metabolites Produced } \\
\text { by Gut Microbiota }\end{array}$} & \multirow{2}{*}{ Type of Cancer (s) } & \multirow{2}{*}{ Targeted Pathways } & \multirow{2}{*}{ Mechanism of Action } & \multirow{2}{*}{ Methods of Testing } & \multicolumn{2}{|c|}{ Model Used } & \multirow{2}{*}{ References } \\
\hline & & & & & & & In Vivo & In Vitro & \\
\hline \multirow{5}{*}{ 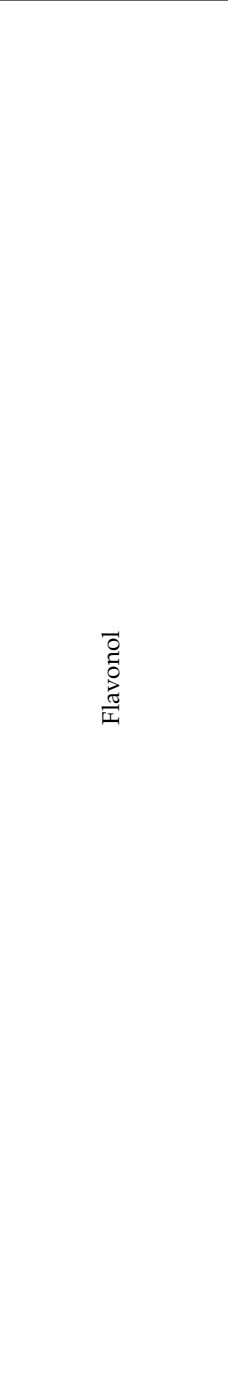 } & 1. Rutin & $\begin{array}{l}\text { Quercetin -3- O- } \\
\text { glucoside } \\
\text { Quercetin }\end{array}$ & $\begin{array}{l}\text { Colorectal cancer } \\
\text { Colonic } \\
\text { adenocarcinoma }\end{array}$ & $\begin{array}{l}\text { Reactive oxygen } \\
\text { species (ROS) } \\
\text { Apoptosis } \\
\text { Angiogenesis }\end{array}$ & $\begin{array}{c}\text { Inhibit tumor cell proliferation } \\
\text { Impaired attachment of cells in } \\
\text { dose-dependent matter } \\
\quad(38 \pm 1.9 \%) \\
\text { Inhibit cell migration } \\
\text { Protect cells from inflammation, } \\
\text { oxidative stress, and DNA damage }\end{array}$ & $\begin{array}{l}\text { Cell viability assay } \\
\text { Cell migration assay } \\
\text { Adhesion assay } \\
\text { Haptotaxis assay }\end{array}$ & $\begin{array}{l}\text { Azoxymethane } \\
\text { (AOM) treated } \\
\text { mice }\end{array}$ & $\begin{array}{l}\text { Caco- } 2 \text { cells } \\
\text { HT29 cells }\end{array}$ & [107-109] \\
\hline & 2. Fisetin & No available data & $\begin{array}{l}\text { Gastric cancer } \\
\text { Colorectal cancer }\end{array}$ & $\begin{array}{c}\text { Apoptosis } \\
\text { Caspase -7 } \\
\text { B-cell lymphoma } 2 \\
\text { (Bcl-2) }\end{array}$ & $\begin{array}{c}\text { Reduce cellular proliferation } \\
\text { significantly } \\
\text { Reduce anti-apoptotic proteins } \\
\text { Reduce the activation of } \\
\text { extracellular- } \\
\text { signal-regulated kinase } 1 / 2 \text { in dose- } \\
\text { dependent matter } \\
\text { Increase the proportion of cells at } \\
\text { G2/M phase } \\
\text { Increase the level of caspase } 7 \\
\text { Induce cellular apoptosis ( } 87 \% \\
\text { after treatment) }\end{array}$ & $\begin{array}{l}\text { Flow cytometry } \\
\text { Western blot } \\
\text { Cell counting kit-8 } \\
\text { assay } \\
\text { Immunoblotting }\end{array}$ & $\begin{array}{l}\mathrm{Apc}^{\mathrm{Min} /+} \text { males } \\
\text { Wistar rats }\end{array}$ & $\begin{array}{l}\text { SGC7901 cells } \\
\text { PIK3CA cells }\end{array}$ & [110] \\
\hline & 3. Kaempferol & $\begin{array}{l}\text { Kaempferol -3-O- } \\
\text { glucoside } \\
\text { p-coumaric acid } \\
\text { kaempferol } \\
\text { 3-(4 hydroxyphenyl) } \\
\text { propionic acid } \\
\text { 3-phenylpropionic acid }\end{array}$ & $\begin{array}{l}\text { Gastric cancer } \\
\text { Colorectal cancer }\end{array}$ & $\begin{array}{l}\text { B-cell lymphoma } 2 \\
\text { (Bcl-2) } \\
\text { Protein kinase B } \\
\text { (Akt) } \\
\text { Cyclooxygenase-2 }\end{array}$ & $\begin{array}{c}\text { Inhibit cellular proliferation } \\
\text { significantly } \\
\text { Inhibit the growth of tumor } \\
\text { xenograft } \\
\text { Reduce the expression level of } \\
\text { cyclin B, Cyclin-dependent kinase } \\
1 \text { and cdc25c phosphatase } \\
\text { Reduce the expression of Bcl-2 } \\
\text { Increase the proportion of cells at } \\
\text { G2/M phase } \\
\text { Increase the level of caspase } 3 \text { and } \\
9 \\
* \text { Induce cellular apoptosis }\end{array}$ & $\begin{array}{l}\text { Cell viability assay } \\
\text { Western blot } \\
\text { Tumor xenograft } \\
\text { experiment } \\
\text { Ki-67 } \\
\text { immunochemistry }\end{array}$ & Mice & $\begin{array}{l}\text { SGC7901 cells } \\
\text { MKN28 cells }\end{array}$ & {$[111,112]$} \\
\hline & 4. Quercetin & $\begin{array}{c}\text { 3,4- } \\
\text { dihydroxyphenylacetic } \\
\text { acid } \\
\text { 3-(3-hydroxyphenyl) } \\
\text { propionic acid } \\
\text { 3,4-dihydroxybenzoic } \\
\text { 4-hydroxybenzoic acid }\end{array}$ & Gastric cancer & $\begin{array}{c}\text { Nuclear factor kappa } \\
\text { (NF- } \mathrm{kB}) \\
\text { Protein kinase B } \\
\text { (Akt) } \\
\text { AMP-activated } \\
\text { protein kinase }\end{array}$ & $\begin{array}{c}\text { Inhibit NF- } \kappa B \text {, AMPKA pathways } \\
\text { Reduce matrix metalloproteinases } \\
\text { Reduce cellular migration and } \\
\text { invasion } \\
\text { Reduce tumor metastasis } \\
\text { Induce cellular apoptosis }\end{array}$ & $\begin{array}{l}\text { Cell viability assay } \\
\text { Western blot } \\
\text { Flow cytometry } \\
\text { Quantitative reverse } \\
\text { transcription PCR }\end{array}$ & Mice & $\begin{array}{c}\text { AGS cells } \\
\text { GCBGC } 823 \text { cells } \\
\text { MGC } 803 \text { cells }\end{array}$ & {$[113,114]$} \\
\hline & 5. Isorhamnetin & $\begin{array}{l}\text { 3-O-neohesperidoside } \\
\text { Isorhamnetin -3- } \\
\text { glucoside } \\
\text { Aglycone isorhamnetin }\end{array}$ & $\begin{array}{l}\text { Gastric cancer } \\
\text { Colorectal cancer }\end{array}$ & $\begin{array}{c}\text { Protein kinase B } \\
\text { (Akt) } \\
\text { Phosphoinositide } \\
\text { 3-kinase } \\
\text { Peroxisome } \\
\text { proliferator- } \\
\text { activated receptor } \\
\text { gamma (PPAR- } \gamma \text { ) }\end{array}$ & $\begin{array}{l}\text { Inhibit cellular proliferation } \\
\text { Reduce the expression of } \\
\text { anti-apoptotic proteins } \\
\text { Reduce cellular invasion } \\
\text { Induce cellular apoptosis } \\
\text { Increase PPAR- } \gamma \text { expression }\end{array}$ & $\begin{array}{l}\text { PPAR- } \gamma \text { competition } \\
\text { assay } \\
\text { Flow cytometry } \\
\text { Western blot } \\
\text { Invasion assay }\end{array}$ & Mice & $\begin{array}{l}\text { AGS cells } \\
\text { MKN45 cells }\end{array}$ & {$[115,116]$} \\
\hline
\end{tabular}


Table 2. Cont.

\begin{tabular}{|c|c|c|c|c|c|c|c|c|c|}
\hline \multirow{3}{*}{ Flavonoid Subclass } & \multirow{2}{*}{$\begin{array}{l}\text { Name of } \\
\text { Flavonoid }\end{array}$} & \multirow{2}{*}{$\begin{array}{l}\text { Metabolites Produced } \\
\text { by Gut Microbiota }\end{array}$} & \multirow{2}{*}{ Type of Cancer (s) } & \multirow{2}{*}{ Targeted Pathways } & \multirow{2}{*}{ Mechanism of Action } & \multirow{2}{*}{ Methods of Testing } & \multicolumn{2}{|c|}{ Model Used } & \multirow{2}{*}{ References } \\
\hline & & & & & & & In Vivo & In Vitro & \\
\hline & 6. Morin & $\begin{array}{l}\text { Morin glucuronides } \\
\text { Morin sulfates }\end{array}$ & Colorectal cancer & $\begin{array}{c}\text { Peroxisome } \\
\text { proliferator- } \\
\text { activated receptor } \\
\text { gamma (PPAR- } \gamma \text { ) } \\
\text { Nuclear factor kappa } \\
\text { (NF-kB) } \\
\text { B-cell lymphoma 2 } \\
\text { (Bcl-2) }\end{array}$ & $\begin{array}{l}\text { Inhibit cellular proliferation in } \\
\text { dose and time dependent matter } \\
\text { Inhibit NF- } \mathrm{B} \text {, AMPKA pathways } \\
\text { Reduce glucose uptake } \\
\text { Reduce antioxidant activities } \\
\text { Reduce ATP production level } \\
\text { Induce cellular apoptosis } \\
\text { Increase PPAR- } \gamma \text { expression }\end{array}$ & $\begin{array}{l}\text { Cell viability assay } \\
\text { Flow cytometry } \\
\text { Immunoblotting } \\
\text { Antioxidant assay }\end{array}$ & & SW480 cells & {$[117,118]$} \\
\hline \multirow{3}{*}{ 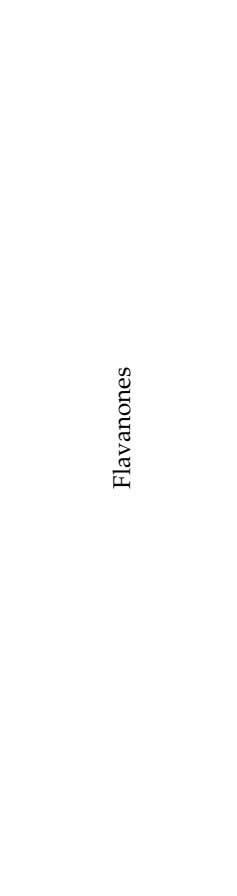 } & 7. Hesperidin & Hesperetin & Gastric cancer & $\begin{array}{c}\text { Mitochondrial } \\
\text { pathway (increase } \\
\text { ROS) } \\
\text { B-cell lymphoma 2 } \\
\text { (Bcl-2) } \\
\text { Cytochrome c } \\
\text { specificity protein 1 } \\
\text { (Sp1) } \\
\text { Phosphatase and } \\
\text { tensin homolog }\end{array}$ & $\begin{array}{c}\text { Inhibit cellular proliferation in } \\
\text { dose and time dependent matter } \\
\text { Inhibit xenograft tumor } \\
\text { Reduce the expression of Bcl-2 } \\
\text { Supress mRNA/protein level of } \\
\text { Sp1 } \\
\text { Reduce ATP production level } \\
\text { Induce cellular apoptosis through } \\
\text { PTEN expression } \\
\text { Increase cytochrome c, caspase } 3 \\
\text { and } 9 \\
\text { expression }\end{array}$ & $\begin{array}{c}\text { Cell viability assay } \\
\text { Western blot } \\
\text { Transwell invasion } \\
\text { assay } \\
\text { Antibody studies }\end{array}$ & Mice & $\begin{array}{l}\text { SGC-7901cells } \\
\text { MGC-803 cells } \\
\text { HGC- } 27 \text { cells }\end{array}$ & {$[119,120]$} \\
\hline & 8. Naringenin & Aglycone naringenin & $\begin{array}{l}\text { Gastric cancer } \\
\text { Colorectal cancer }\end{array}$ & $\begin{array}{l}\text { B-cell lymphoma } 2 \\
\text { (Bcl-2) } \\
\text { Cyclin D1 protein } \\
\text { Prostaglandin- } \\
\text { endoperoxide } \\
\text { synthase 2 (COX-2) }\end{array}$ & $\begin{array}{c}\text { Inhibit cellular proliferation in } \\
\text { dose and time dependent matter } \\
\text { Reduce cellular migration and } \\
\text { invasion } \\
\text { Reduce the expression of Bcl-2 } \\
\text { Reduce cyclin D1 protein } \\
\text { Induce cellular apoptosis } \\
\text { Increase the level of cleaved } \\
\text { caspase }\end{array}$ & $\begin{array}{l}\text { Quantitative reverse } \\
\text { transcription PCR } \\
\text { Western blot } \\
\text { Proliferating cell } \\
\text { nuclear antigen } \\
\text { (PCNA) }\end{array}$ & $\begin{array}{c}\text { Azoxymethane } \\
(\mathrm{AOM}) \text { treated } \\
\text { rats } \\
\text { Wistar rats }\end{array}$ & $\begin{array}{l}\text { SGC-7901cells } \\
\text { SW480 cells } \\
\text { HCT-116 cells }\end{array}$ & {$[121,122]$} \\
\hline & 9. Eriodictyol & Eriocitrin & Colorectal cancer & $\begin{array}{c}\beta \text {-glucuronidase } \\
\text { Lipid peroxidation } \\
\text { Superoxide } \\
\text { dismutase (SOD) } \\
\text { catalase (CAT) }\end{array}$ & $\begin{array}{l}\text { Supress cellular proliferation } \\
\text { Reduce lipid peroxidation levels } \\
\text { Reduce aberrant crypt foci } \\
\text { Reduce microbial enzymatic } \\
\text { activities in feces } \\
\text { Reduce Argyrophilic nucleolar } \\
\text { organizer region (AgNOR) } \\
\text { Induce cellular apoptosis } \\
\text { Increase the level of cleaved } \\
\text { caspase }\end{array}$ & $\begin{array}{c}\text { AgNOR staining } \\
\text { Bacterial enzymes } \\
\text { assay } \\
\text { Lipid peroxidation } \\
\text { Histopathological } \\
\text { assays }\end{array}$ & Albino wistar rats & & [123] \\
\hline
\end{tabular}


Table 2. Cont.

\begin{tabular}{|c|c|c|c|c|c|c|c|c|c|}
\hline \multirow{2}{*}{ Flavonoid Subclass } & \multirow{2}{*}{$\begin{array}{l}\text { Name of } \\
\text { Flavonoid }\end{array}$} & \multirow{2}{*}{$\begin{array}{l}\text { Metabolites Produced } \\
\text { by Gut Microbiota }\end{array}$} & \multirow{2}{*}{ Type of Cancer (s) } & \multirow{2}{*}{ Targeted Pathways } & \multirow{2}{*}{ Mechanism of Action } & \multirow{2}{*}{ Methods of Testing } & \multicolumn{2}{|c|}{ Model Used } & \multirow{2}{*}{ References } \\
\hline & & & & & & & In Vivo & In Vitro & \\
\hline \multirow[t]{2}{*}{ 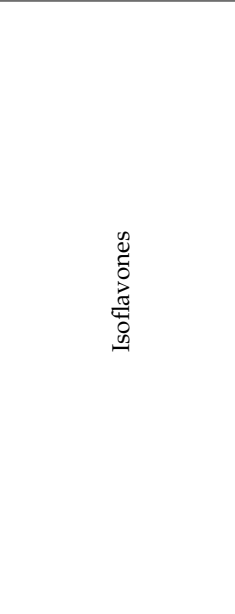 } & 10. Genistein & $\begin{array}{l}\text { Dihydrogenistein } \\
\text { 6-hydroxy-O- } \\
\text { desmethylangolensin } \\
\text { 2-(4-hydroxyphenyl) } \\
\text { propionic acid }\end{array}$ & $\begin{array}{l}\text { Gastric cancer } \\
\text { Colorectal cancer }\end{array}$ & $\begin{array}{l}\text { Protein kinase B } \\
\text { (Akt) } \\
\text { Notch1 signaling } \\
\text { E-cadherins } \\
\text { Nuclear factor kappa } \\
\text { (NF- } \mathrm{kB} \text { ) }\end{array}$ & $\begin{array}{c}\text { Blocked high cell migration } \\
\text { capacity } \\
\text { of CD44 } \\
\text { Reduce Glil and CD44 expression } \\
\text { Supress cellular invasion and } \\
\text { metastasis } \\
\text { Decrease epithelial-mesenchymal } \\
\text { transition (EMT) expression } \\
\text { Inhibit Notch1 and NF- KB } \\
\text { expression } \\
\text { Induce cellular apoptosis } \\
\text { Increase E-cadherins and caspase } 3 \\
\text { expression }\end{array}$ & $\begin{array}{l}\text { Colony formation } \\
\text { assay } \\
\text { Western blot } \\
\text { Flow cytometry } \\
\text { Real time } \\
\text { polymerase chain } \\
\text { reaction } \\
\text { Immunofluorescence }\end{array}$ & & $\begin{array}{l}\text { MKN } 45 \text { cells } \\
\text { HT-29 cells } \\
\text { HCT-116 cells }\end{array}$ & {$[124,125]$} \\
\hline & 11. Daidzein & $\begin{array}{c}\text { Dihydrodaidzein } \\
\text { O- } \\
\text { desmethylangolensin } \\
\text { S- equol }\end{array}$ & $\begin{array}{l}\text { Colorectal cancer } \\
\text { Choriocarcinoma }\end{array}$ & $\begin{array}{c}\text { Peroxisome } \\
\text { proliferator- } \\
\text { activated receptor } \\
\text { gamma (PPAR- } \gamma \text { ) } \\
\text { Extracellular-signal- } \\
\text { regulated kinase } \\
\text { (P-ERK) }\end{array}$ & $\begin{array}{l}\text { Reduce lipid droplet accumulation } \\
\text { Reduce Phosphoinositide 3-kinase } \\
\text { (PI3K) expression } \\
\text { Inhibit cellular proliferation } \\
\text { Reduce the expression of P-ERK } \\
\text { Induce cellular apoptosis } \\
\text { Induce m-RNA expression of } \\
\text { PPAR- } \gamma\end{array}$ & $\begin{array}{l}\text { Colony formation } \\
\text { assay } \\
\text { Western blot } \\
\text { Flow cytometry } \\
\text { Real time } \\
\text { polymerase chain } \\
\text { reaction } \\
\text { Immunofluorescence }\end{array}$ & Nude mice & $\begin{array}{l}\text { JAR cells } \\
\text { JEG-3 cells } \\
\text { HT- } 29 \text { cells }\end{array}$ & [126] \\
\hline \multirow{3}{*}{ 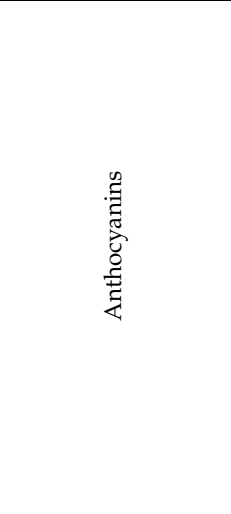 } & 12. Cyanidin & Cyanidin-3- glucoside & $\begin{array}{c}\text { Gastric } \\
\text { adenocarcinoma }\end{array}$ & $\begin{array}{l}\text { Combined activity of } \\
\text { bacteria and host } \\
\text { enzymes }\end{array}$ & $\begin{array}{l}\text { Reduce cellular proliferation } \\
\text { Induce cellular apoptosis through } \\
\text { caspase- } 3 \text { activation }\end{array}$ & $\begin{array}{l}\text { Cell viability assay } \\
\text { High-performance } \\
\text { liquid } \\
\text { chromatography } \\
\text { (HPLC) }\end{array}$ & & AGS cells & [127] \\
\hline & 13. Delphinidin & Gallic acids & Colorectal cancer & $\begin{array}{c}\alpha \mathrm{V} / \beta 3 \text {-integrin } \\
\text { miR-204-3p }\end{array}$ & $\begin{array}{c}\text { Inhibit colony formation } \\
\text { Reduce cellular viability (not } \\
\text { significant) } \\
\text { Inhibit migration and invasion } \\
\text { through } \alpha \mathrm{V} / \beta 3 \text {-integrin } \\
\text { reduction and miR-204-3p } \\
\text { enhancement } \\
\end{array}$ & $\begin{array}{l}\text { Colony formation } \\
\text { assay } \\
\text { Western blot } \\
\text { Flow cytometry } \\
\text { Microarray }\end{array}$ & $\begin{array}{l}\text { BALB/C nude } \\
\text { mice }\end{array}$ & $\begin{array}{l}\text { SW480 cells } \\
\text { SW620 cells }\end{array}$ & [128] \\
\hline & 14. Pelargonidin & 4-hydroxybenzoic & Colorectal cancer & Apoptotic pathway & $\begin{array}{c}\text { Reduce the expression of Bcl-2 } \\
\text { Induce cellular apoptosis through } \\
\text { intrinsic pathway } \\
\text { Induce the loss of mitochondrial } \\
\text { membrane potential }\end{array}$ & $\begin{array}{l}\text { Cell viability assay } \\
\text { Western blot }\end{array}$ & & HT-29 cells & [129] \\
\hline
\end{tabular}


Table 2. Cont

\begin{tabular}{|c|c|c|c|c|c|c|c|c|c|}
\hline \multirow{2}{*}{ Flavonoid Subclass } & \multirow{2}{*}{$\begin{array}{c}\text { Name of } \\
\text { Flavonoid }\end{array}$} & \multirow{2}{*}{$\begin{array}{l}\text { Metabolites Produced } \\
\text { by Gut Microbiota }\end{array}$} & \multirow{2}{*}{ Type of Cancer (s) } & \multirow{2}{*}{ Targeted Pathways } & \multirow{2}{*}{ Mechanism of Action } & \multirow{2}{*}{ Methods of Testing } & \multicolumn{2}{|c|}{ Model Used } & \multirow{2}{*}{ Reference } \\
\hline & & & & & & & In Vivo & In Vitro & \\
\hline \multirow{5}{*}{ 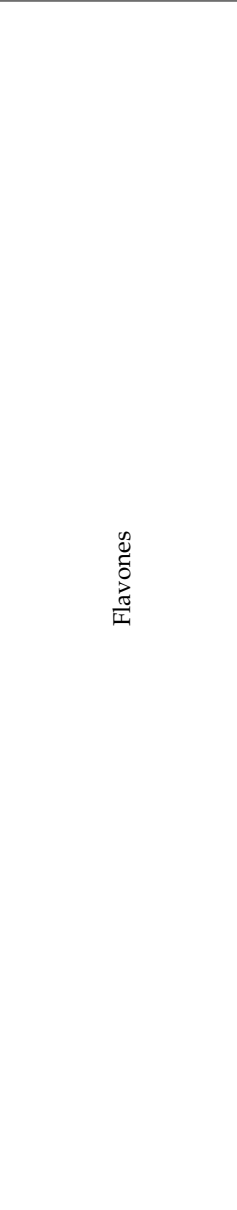 } & 15. Baicalein & Baicalein & $\begin{array}{l}\text { Gastric cancer } \\
\text { Colorectal cancer }\end{array}$ & $\begin{array}{l}\text { Inhibitory cell cycle } \\
\text { proteins } \\
\text { E-cadherins } \\
\text { epithelial- } \\
\text { mesenchymal } \\
\text { transition (EMT) }\end{array}$ & $\begin{array}{l}\text { Supress cellular proliferation, } \\
\text { migration and invasion in dose } \\
\text { and time dependent matter } \\
\text { Decrease the expression of EMT } \\
\text { Induce cellular apoptosis } \\
\text { Increase the expression of E- } \\
\text { cadherins } \\
\text { Increase the level of cell cycle } \\
\text { inhibitory proteins (P53 and P21) }\end{array}$ & $\begin{array}{l}\text { Flow cytometry } \\
\text { Western blot } \\
\text { Cell counting kit-8 } \\
\text { assay } \\
\text { Transwell assay } \\
\text { Colony formation } \\
\text { assay } \\
\text { Real time } \\
\text { polymerase chain } \\
\text { reaction }\end{array}$ & Mice & $\begin{array}{l}\text { SGC-7901cells } \\
\text { SW480 cells } \\
\text { HCT-116 cells } \\
\text { HT-29 cells }\end{array}$ & {$[130,131]$} \\
\hline & 16. Luteolin & No available data & $\begin{array}{l}\text { Gastric cancer } \\
\text { Colorectal cancer }\end{array}$ & $\begin{array}{c}\text { E-cadherins } \\
\text { epithelial- } \\
\text { mesenchymal } \\
\text { transition (EMT) } \\
\text { Protein kinase B } \\
\text { (Akt) } \\
\text { Mechanistic target of } \\
\text { rapamycin (mTOR) } \\
\text { Notch1 signaling }\end{array}$ & $\begin{array}{l}\text { Reduce cellular viability in time } \\
\text { and dose dependent matter } \\
\text { Inhibit cellular proliferation, } \\
\text { migration and invasion } \\
\text { Reduce aberrant crypt foci } \\
\text { Decrease the expression of EMT by } \\
\text { increasing E-cadherins and } \\
\text { decreasing Notch1 signaling } \\
\text { Induce cellular apoptosis }\end{array}$ & $\begin{array}{l}\text { Flow cytometry } \\
\text { Western blot } \\
\text { Cell viability assay } \\
\text { Xenograft assay }\end{array}$ & Mice & $\begin{array}{l}\text { SGC-7901cells } \\
\text { MKN } 45 \text { cells } \\
\text { BGC-832 cells }\end{array}$ & {$[132,133]$} \\
\hline & 17. Diosmin & Diosmetin & Colorectal cancer & No available data & $\begin{array}{l}\text { Inhibit aberrant crypt foci } \\
\text { Reduce cellular proliferation }\end{array}$ & $\begin{array}{c}\text { Histopathological } \\
\text { assays } \\
\text { Microscopic } \\
\text { evaluation }\end{array}$ & $\begin{array}{l}\text { Azoxymethane } \\
\text { (AOM) treated } \\
\text { rats }\end{array}$ & & [134] \\
\hline & 18. Apigenin & $\begin{array}{c}\text { Apigenin } \\
\text { 3-(4-hydroxyphenyl) } \\
\text { propionic acid }\end{array}$ & $\begin{array}{l}\text { Gastric cancer } \\
\text { Colorectal cancer }\end{array}$ & $\begin{array}{c}\beta \text {-catenin } \\
\text { B-cell lymphoma } 2 \\
\text { (Bcl-2) }\end{array}$ & $\begin{array}{l}\text { Reduce mitochondrial membrane } \\
\text { potential } \\
\text { Inhibit cellular proliferation } \\
\text { Reduce the expression of Bcl-2 } \\
\text { Increase the expression of caspase } \\
3 \text { Induce cellular apoptosis } \\
\text { through intrinsic and extrinsic } \\
\text { pathways }\end{array}$ & $\begin{array}{c}\text { Flow cytometry } \\
\text { Western blot } \\
\text { Cell viability assay } \\
\text { Real time } \\
\text { polymerase chain } \\
\text { reaction }\end{array}$ & & $\begin{array}{l}\text { SGC-7901cells } \\
\text { HCT-116 cells } \\
\text { HGC-27 cells }\end{array}$ & {$[135,136]$} \\
\hline & 19. Tangeretin & $\begin{array}{l}\text { Tangeretin-O- } \\
\text { glucuronides }\end{array}$ & Gastric cancer & Notch1 signaling & $\begin{array}{c}\text { Reduce cellular viability, invasion } \\
\text { and } \\
\text { migration } \\
\text { Inhibit Notch1 signaling pathway } \\
\text { Decrease the expression of EMT by } \\
\text { increasing E-cadherins } \\
\text { Increase caspase } 3 \text { and } 9 \\
\text { expression } \\
\text { Induce cellular apoptosis through } \\
\text { intrinsic and extrinsic pathways }\end{array}$ & $\begin{array}{l}\text { Flow cytometry } \\
\text { Western blot } \\
\text { Cell viability assay } \\
\text { Microarray }\end{array}$ & Nude mice & $\begin{array}{l}\text { AGS cells } \\
\text { MKN-45 cells } \\
\text { MGC } 80-3 \text { cells }\end{array}$ & {$[137,138]$} \\
\hline
\end{tabular}


Table 2. Cont.

\begin{tabular}{|c|c|c|c|c|c|c|c|c|c|}
\hline \multirow{4}{*}{ Flavonoid Subclass } & \multirow{2}{*}{$\begin{array}{l}\text { Name of } \\
\text { Flavonoid }\end{array}$} & \multirow{2}{*}{$\begin{array}{l}\text { Metabolites Produced } \\
\text { by Gut Microbiota }\end{array}$} & \multirow{2}{*}{ Type of Cancer (s) } & \multirow{2}{*}{ Targeted Pathways } & \multirow{2}{*}{ Mechanism of Action } & \multirow{2}{*}{ Methods of Testing } & \multicolumn{2}{|c|}{ Model Used } & \multirow{2}{*}{ References } \\
\hline & & & & & & & In Vivo & In Vitro & \\
\hline & 20. Wogonin & Wogonin & $\begin{array}{l}\text { Gastric cancer } \\
\text { Colorectal cancer }\end{array}$ & P53 translocation & $\begin{array}{l}\text { Reduce tumor multiplicity } \\
\text { Induce cellular apoptosis through } \\
\text { increase endoplasmic reticulum } \\
\text { stress }\end{array}$ & $\begin{array}{l}\text { Flow cytometry } \\
\text { Western blot } \\
\text { Cell viability assay } \\
\text { Real time } \\
\text { polymerase chain } \\
\text { reaction }\end{array}$ & $\begin{array}{l}\text { Azoxymethane } \\
\text { (AOM) treated } \\
\text { mice }\end{array}$ & HCT-116 cells & {$[139,140]$} \\
\hline & 21. Chrysin & & $\begin{array}{l}\text { Gastric cancer } \\
\text { Colorectal cancer }\end{array}$ & $\begin{array}{l}\text { Nuclear factor kappa } \\
\text { (NF-kB) } \\
\text { SALL-4 } \\
\text { Early growth } \\
\text { response 1 (Egr1) }\end{array}$ & $\begin{array}{c}\text { Reduce tumor volume by } \\
\text { downregulating SALL-4 } \\
\text { expression } \\
\text { Reduce cellular proliferation } \\
\text { Supress the expression of NF-KB } \\
\text { and Egr1 } \\
\text { Increase caspase } 3 \text { and } 9 \\
\text { expression } \\
\text { Induce cellular apoptosis through } \\
\text { intrinsic pathway (caspase } 3 \text { and 9) }\end{array}$ & $\begin{array}{l}\text { Flow cytometry } \\
\text { Western blot } \\
\text { Cell viability assay } \\
\text { Quantitative reverse } \\
\text { transcription PCR } \\
\text { Apoptotic assays }\end{array}$ & BALB $/$ mice & $\begin{array}{l}\text { HT- } 29 \text { cells } \\
\text { CT- } 26 \text { cells }\end{array}$ & [141] \\
\hline
\end{tabular}




\subsection{Flavonoids Effects on Impaired General Pathways}

\subsubsection{Apoptosis}

A process described as programmed cell death is characterized by the changes in the biochemical mechanisms and the morphological characteristics of the cell [142]. It is considered a critical component of various biological processes such as embryonic development, chemical-induced cell death and normal cell turnover [143]. A wide variety of pathological and physiological stimuli and conditions could trigger apoptosis [144]. Unregulated apoptosis can result in neurodegenerative, autoimmune diseases and cancer [145]. In cancer, apoptosis is considered the hallmark for cell survival, invasiveness and cellular proliferation. There are multiple ways in which cancer cells can evade intrinsic and extrinsic apoptotic pathways, such as inhibition of caspase function and upregulation of anti-apoptotic BCL-2 proteins [146].

Consumption of flavonoids is reported to induce apoptosis in GI cancer, acting as a potential therapeutic agent [147]. Flavonoids could induce apoptosis by acting on the intrinsic apoptotic pathway, as in the case of fisetin. Gastric cancer cells treated with $(25-100 \mu \mathrm{M})$ of fisetin induced apoptosis by dissipating mitochondrial potential and upregulating pro-apoptotic molecules such as Bcl-2 and tumor suppressors such as P53 [148]. Additionally, other flavonoids such as cyanidin upregulate the expression of caspase 3, therefore activating the extrinsic apoptotic pathway in human gastric adenocarcinoma cells [127]. While some flavonoids target one specific pathway, other targets both intrinsic and extrinsic pathways such as apigenin in colorectal cancer cells or, as in the case of hesperidin, flavonoids can target multiple components of the same pathway $[119,135]$. Figure 3 summarizes reported flavonoids that induce apoptosis of GI cancer cells and their target's key components.

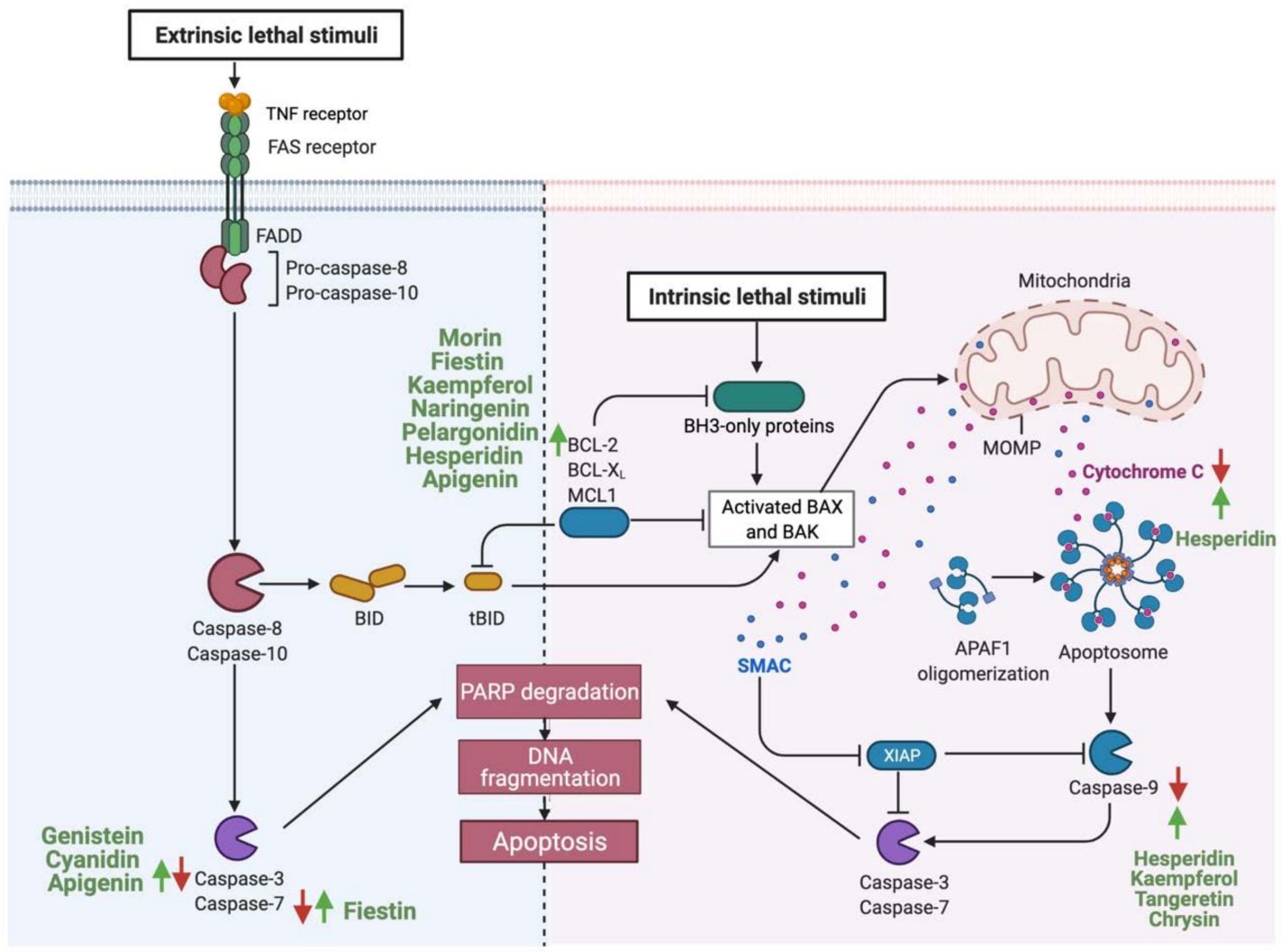

Figure 3. Schematic illustration of the impact of flavonoids on the apoptotic pathway. The figure is divided into two sections. In the right section, flavonoids targeting the intrinsic pathways are high-lighted, and in the left sections, the extrinsic pathways. Red arrows represent the effects of GI cancer on pathways, while the green arrows for flavonoids effect. Adapted from “Apoptosis", by BioRender.com (accessed on 3 August 2021). 


\subsubsection{Cellular Proliferation}

Cellular proliferation is a fundamental process for homeostasis and cellular development that is tightly regulated to ensure accurate genome duplication $[149,150]$. Phosphatidylinositol-3-kinase (PI3K)/AKT/mammalian target of rapamycin (mTOR) pathway is one of the most critical intracellular pathways to regulate cellular survival, growth, motility and metabolism [151]. Under baseline conditions, PI3K is activated by an external stimulus such as cytokines, hormones and growth factors. Upon activation, phosphorylation yields a second messenger (PIP3) that binds and recruits lipid-binding domains that target cell membrane. Signaling proteins such as AKT kinase binds to PI3K to activate cellular growth [152]. Phosphatase and tensin homolog (PTEN) regulate the pathway by the dephosphorylation of PI3K, thus preventing downstream activation [153]. In cancer, PI3K pathway can be downregulated by the inactivation of PTEN (tumor suppressor), mutation of PI3K and activation of tyrosine kinase [154].

Flavonoids such as hesperidin can inhibit the proliferation of cancer cells [155]. In an in vivo and in vitro study, the results provided strong evidence that hesperidin enhances antitumor effects on gastric cancer by regulating PI3K/AKT signaling pathway through the upregulation of PTEN expression. In addition, a combinatory therapy of cisplatin with hesperidin could enhance the clinical outcome [120]. Additionally, luteolin can inhibit cellular proliferation by regulating PI3K, AKT and mTOR signaling pathways, which play a key role in the progression and development of gastric cancer [132]. Figure 4 highlights the reported activities of flavonoids affecting GI cancer cells proliferation.

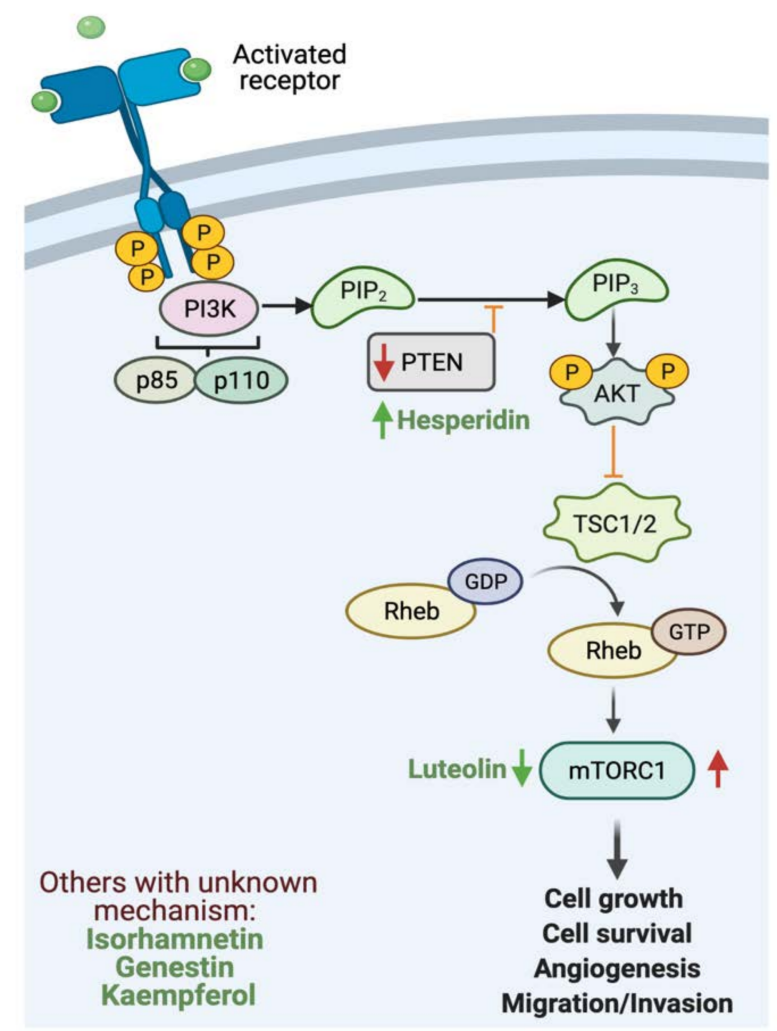

Figure 4. Schematic illustration of the impact of flavonoids on cellular proliferation. The figure illustrates PI3K pathway. Red arrows represent the effects of GI cancer on the pathway, while the green arrows for flavonoids effect. Adapted from "PI3K/Akt, RAS/MAPK, JAK/STAT signaling", by BioRender.com (accessed on 3 August 2021).

\subsubsection{Inflammation}

Inflammation is a biological response of the immune system to harmful stimuli such as damaged cells, toxic compounds and pathogens [156]. Nuclear factor $\kappa B(N F-\kappa B)$ 
is a transcription factor that regulates the immune and inflammatory responses and is considered a major proinflammatory gene function mediator [157]. Two major pathways are involved in the activation of NF- $\mathrm{KB}$, the canonical and noncanonical [158]. Upon activation by stimuli, phosphorylation by multi-subunit kinase occurs to induce degradation of IкB $\alpha$. Proteasomal degradation of IKB results in the rapid and transient tumor translocation of P50/RelA and P50/c Rel dimers [159]. NF-KB pathway in tumor cells is constitutively active, and its suppression inhibits the growth of tumor cells [160]. Alternative therapeutic approaches to deactivate NF- $\mathrm{kB}$ are required.

Natural compounds, including flavonoids, were reported to potentially reduce inflammation in GI cancer [161,162]. The treatment of human gastric adenocarcinoma cell-line (AGS) with quercetin $(10 \mu \mathrm{M})$ for $72 \mathrm{~h}$ inhibited the activation of NF- $k B$ through the reduction of p65 phosphorylation, suggesting that quercetin can hamper NF- $k B$ pathway activation and act as a potential anti-inflammatory agent [163]. Additionally, the administration of genistein inhibits NF- $\mathrm{kB}$ expression in colon cancer cells, thus reducing inflammation and suppressing tumor cell migration [164]. Moreover, chrysin administration can indirectly block NF-KB activation by suppressing Recepteur d'origine Nantais (RON), a member of c-Met family, critical for invasion in gastric adenocarcinoma [165]. Figure 5 illustrates the reported anti-inflammatory activities of selected flavonoids utilizable in GI cancer management.

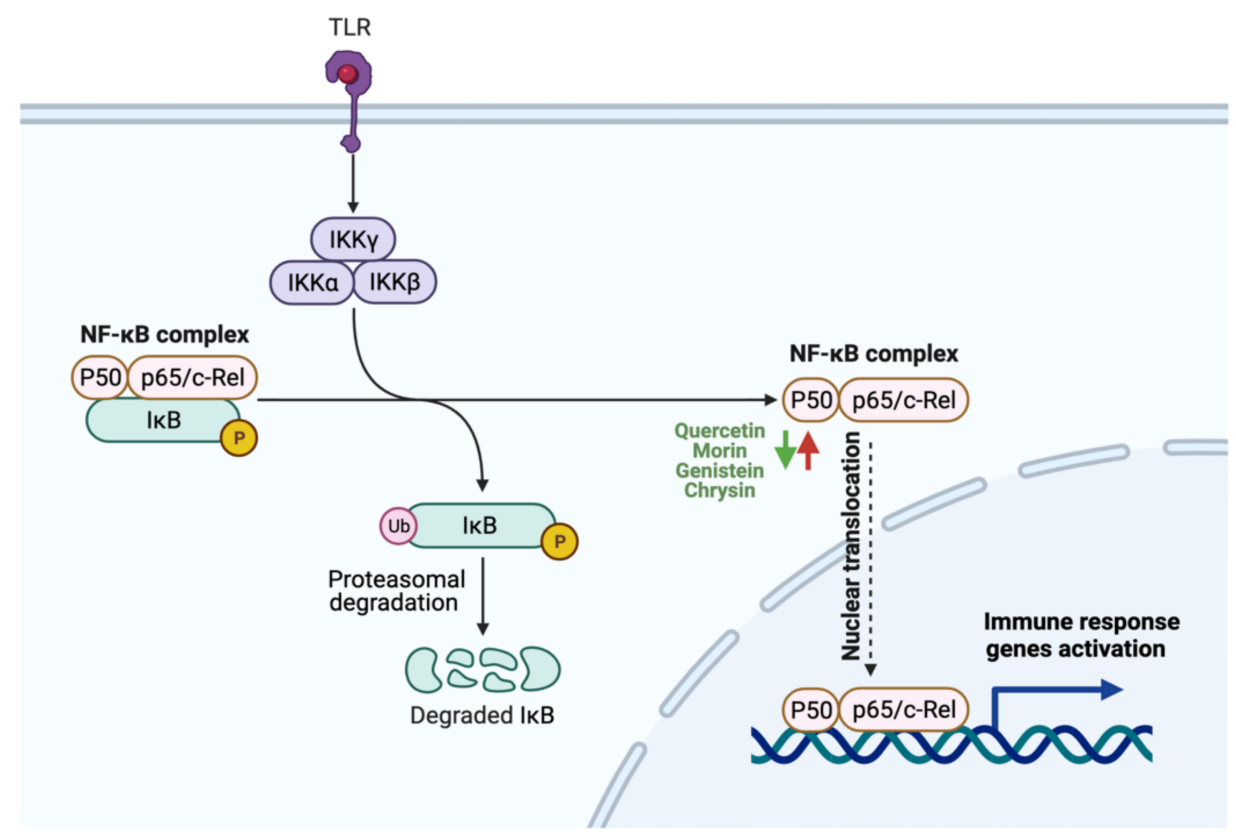

Figure 5. Schematic illustration of the impact of flavonoids on inflammation. The figure illustrates NF- $\kappa$ B complex activation. Red arrows represent the effects of GI cancer on the pathway, while the green arrows for flavonoids effect. Adapted from "NF- $\kappa$ B signaling pathway", by BioRender.com (accessed on 3 August 2021).

\subsubsection{Metastasis}

Cancer metastasis is the spread of cancerous cells to organs and tissues beyond the original tumor site. It is considered the leading cause of mortality in patients with cancer [166]. Five key steps in metastasis are reported: intravasation, invasion, circulation, extravasation and colonization [167]. Metastasis cascade is dependent on the loss of adhesion between cells which results in the separation from the primary tumor [168]. Ecadherin, the most abundant integral protein in epithelia, is reported to play a pivotal role in controlling cancer spread and dissociation, as tumor invasion and metastasis often coincide with the loss of E-cadherin function [169]. Additionally, E-cadherin is considered a tumor suppressor, giving its critical role in the downregulation of the epithelial-mesenchymal transition (EMT) process and the formation of proper intracellular junction [170]. 
Flavonoids show potent anti-cancer effects by regulating critical signaling pathways involved in cancer cells' metastatic progression, migration, and invasion [105]. It was reported recently that chrysin and apigenin showed the synergistic capacity to inhibit the development and metastasis of colorectal cancer [171]. Indeed, flavonoids such as genistein, baicalein, luteolin and tangeretin can enhance the expression of E-cadherin in GI cancer. The effect of genistein on EMT was investigated in colon cancer using HT-29 cells [164]. At $200 \mu \mathrm{mol} / \mathrm{L}$ genistein could inhibit tumor migration through the upregulation of Ecadherin expression, suggesting a potential anti-metastatic agent for colon cancer.

Additionally, using ultra-high-performance liquid chromatography, baicalein reduced the expression of EMT and enhanced E-cadherin expression in colon cancer cells [130]. In addition, gastric cancer metastasis and progression were inhibited significantly after the administration of luteolin and tangeretin [137,172]. Luteolin could reverse EMT expression through the induction of E-cadherin expression, and the downregulation of Snail and vimentin, and tangeretin reduced the expression of EMT. Figure 6 represents a schematic illustration of the reported anti-metastatic effects of flavonoids in GI cancers.

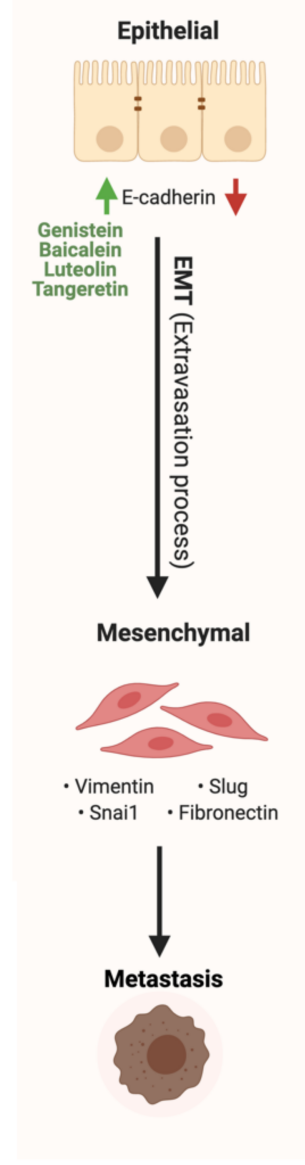

Figure 6. Schematic illustration of the impact of flavonoids on metastasis and EMT pathway. Red arrows represent the effects of GI cancer on the pathway, while the green arrows illustrate the impact of flavonoids on the pathway. Created with BioRender.com (accessed on 3 August 2021).

\subsection{Flavonoids Effects on Impaired Specific Pathways}

The literature review revealed that flavonoids target and positively affect three pathways in GI cancer. Diazedine could inhibit choriocarcinoma cellular proliferation through the suppression of the extracellular-signal-regulated kinase (ERK) pathway by inhibiting p-ERK expression and translocation, as illustrated in Figure 7 [126]. Additionally, Figure 8 illustrates the mechanisms in which the metastasis of colon cancer was inhibited after the administration of dietary delphinidin. Treatment of colon cancer cells lines such as sw480 
with delphinidin $(<100 \mu \mathrm{M})$ suppressed the invasiveness of cell lines and downregulated the integrin signaling pathway, critical for cell adhesion and migration [128]. Moreover, baicalein administration on cells undergoing stress could result in cellular cycle arrest through the activation of p53, as shown in Figure 9 [173]. More efforts are required to understand the underlying mechanism and the potential of using them in cancer therapy.
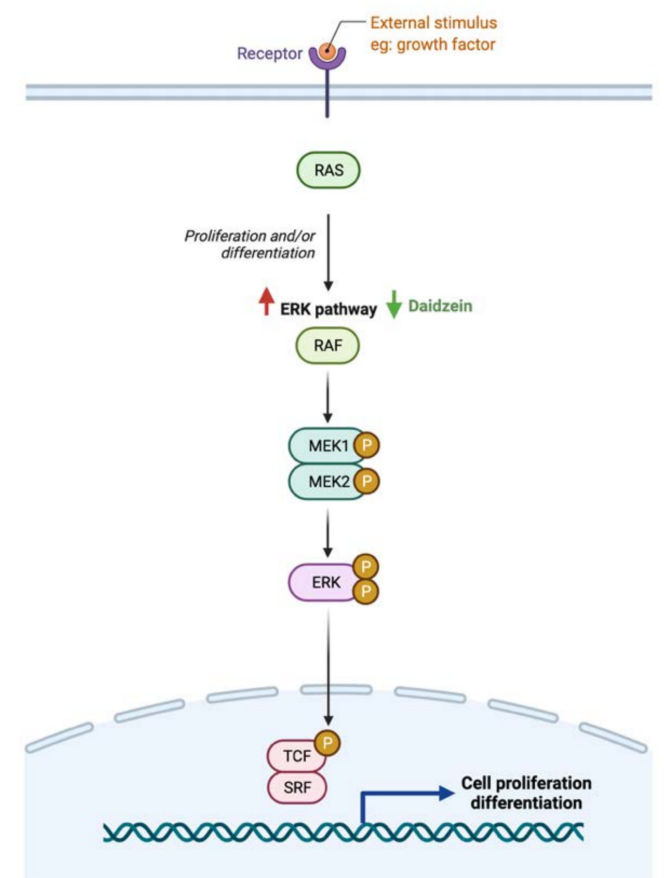

Figure 7. Schematic illustration of the impact of flavonoids on ERK pathway. Red arrows represent the effects of GI cancer on the pathway, while the green arrows illustrate the impact of flavonoids on the pathway. Created with BioRender.com (accessed on 3 August 2021).

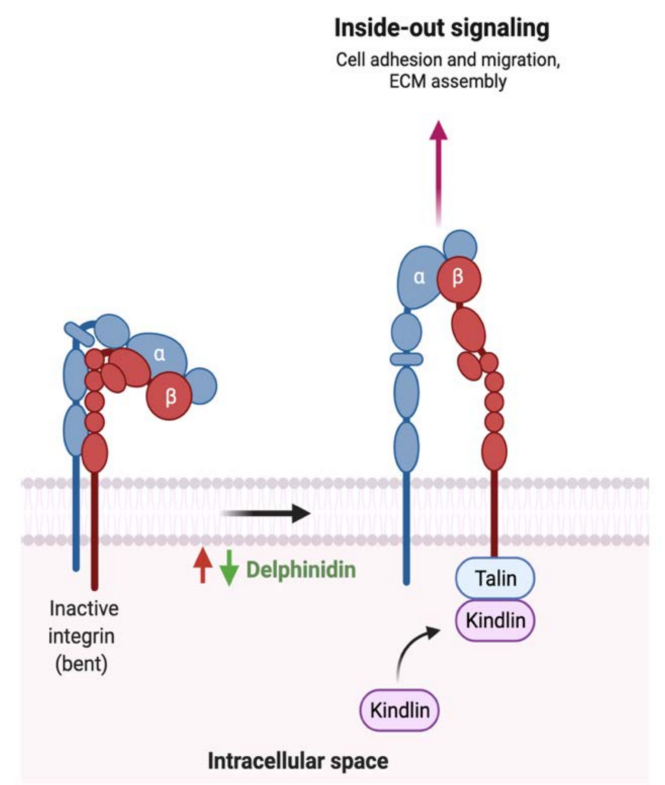

Figure 8. Schematic illustration of the impact of flavonoids on integrin activation. Red arrows represent the effects of GI cancer on the pathway, while the green arrows illustrate the impact of flavonoids on the pathway. Adapted from "Outside-in and Inside-out Integrin Signaling Pathways", by BioRender.com (accessed on 3 August 2021). 


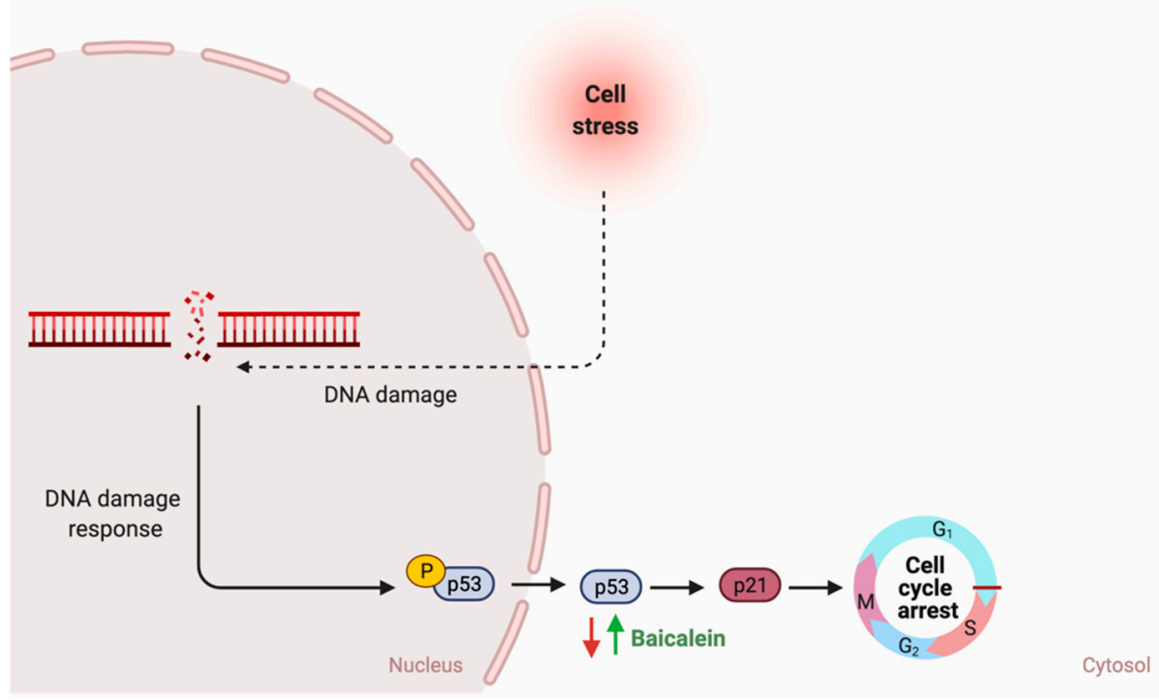

Figure 9. Schematic illustration of the impact of flavonoids on cell cycle arrest. Red arrows represent the effects of GI cancer on the pathway, while the green arrows illustrate the impact of flavonoids on the pathway. Created with BioRender.com (accessed on 3 August 2021).

\section{Discussion}

\subsection{Clinical Implementation of Flavonoids}

As illustrated in Section 4, flavonoids implementation in GI cancer treatments has tumor-suppressive activities in theory. To effectively use flavonoids in cancer therapy, clinical trials are required to assess the impact of flavonoids subclass on GI cancer and gut enzymes. In 2003, flavopiridol, a synthetic flavone reported to inhibit cell cycle progression, was evaluated in 20 patients with advanced colorectal cancer. The patients received flavopiridol at a dose of $50 \mathrm{mg} / \mathrm{m}^{2} /$ day every 14 days via continuous infusion for eight weeks. The phase II clinical trial results reported minimal hematological activities and moderate diarrhea and fatigue in the 20 patients. Even though the pre-clinical data showed promising antitumor activities, no impartial response was observed as only $28 \%$ of the patients experienced stabilization of the disease [174]. Limited studies are reported in the literature, and more are required to evaluate the appropriate dose-administered, the appropriate stage of the disease that tolerates flavonoids administration, and the impact of combination therapy (flavonoids and chemotherapy or a mixture of flavonoids) have synergistic effects on gut enzymes and GI cancer.

\subsection{Impact of Current Cancer Treatment on Gut Enzymes}

The field of modern oncology has produced significant advances in cancer treatment, improving and prolonging patient's lives [175]. Due to observed long-term side effects on cancer survivors, cancer microbiome research that addresses the crucial role of the gut microbiome in improving the efficacy of cancer therapy is rapidly emerging [176]. Chemotherapy can have devastating effects on microbial diversity leading to gastrointestinal toxicities, acute dysbiosis and delaying the response to treatment. Modulation of the gut microbiome was suggested as a practical therapeutic approach to improving cancer treatment's toxic side effects [177]. Lactobacillus and Bifidobacterium along with one digestive enzyme were evaluated for their efficacy in protecting the GI tract after chemotherapy treatment. The results showed an improvement in the colon's fermentation process and the recovery of microbial population in which the ratio of Bacteroidetes to Firmicutes was restored, inducing microbial metabolites production and enhancing anti-inflammatory response [178]. 
Moreover, a combination of rutin and chemotherapeutic agent Oxaliplatin promoted apoptosis of gastric cancer cells SGC-7901 demonstrated through decreased BCL-2/Bax ratio while the apoptotic mechanisms of rutin were related to caspase-mediated signaling [179]. In addition, luteolin combined with Oxaliplatin, suppressed proliferation and induced apoptosis in gastric cancer SGC-7901 cells through cleaved caspase-3, upregulated Bax and downregulated Bcl-2 [133]. More efforts are required to address the impact of cancer treatment on gut enzymatic activities (enhancement/depletion) and natural product metabolism.

\subsection{Fecal Transplantation: Could It Be the Solution?}

Fecal microbiota transplant (FMT) is defined as the transplantation of a fecal solution from a selected donor into the GI tract of a patient to change and restore microbial composition posing as a powerful and effective therapy method [180]. In cancer therapy, laboratory mice transplanted with intestinal microbes from wild mice reported better colorectal cancer resistance than the control [181]. Even though FMT presents a promising therapeutic strategy, efforts are required to identify its safety and efficacy, possible side effects and the possibility of restoring gut enzyme activities required for flavonoids metabolism. Furthermore, additional efforts are needed to propose a strategy where current cancer treatments and FMT could be used, resulting in a synergistic and compelling effect.

\subsection{Challenges with Studying the Field}

The microbiome field has received attention over the last 15 years; however, putative key issues and misinterpretation still pose a problem. Efforts are required to identify the appropriate level to investigate microbial composition (phylum, genus, species). Additionally, microbes in the gut are in a complex community. Therefore, identifying a single microorganism and correlating it to a particular disease without supporting evidence may negatively impact the field. The gut microbiome composition is influenced by multiple factors such as genetic, environment, lifestyle, diet and geographical distribution [182]. Developing a tool or a strategy to standardized experimental activities to allow generalized results interpretation is a necessity.

\subsection{Estimated Flavonoid Concentration and Anti-Cancer Effects}

The total consumption level of flavonoids in a day is reported to range from 11 to 600 $\mathrm{mg}$ depending on geographical location, food processing methods, flavonoids solubility and dietary habits [12]. In most of the reviewed studies and based on the flavonoids tested, method of purification, model and cell lines used and the method of inoculation, variations in the concentration were observed. For example, in a study evaluating the impact of rutin on cellular proliferation in colorectal cancer, the concentration used to achieve the significant proliferation reduction ranged from 31.25 to $1000 \mu \mathrm{M}$ (72 h study period) [107]. On the other hand, quercetin induced apoptosis in gastric cancer cells with a concentration ranging from 3.125 to $400 \mu \mathrm{M}$ (48 h study period) [113]. Even though both studies purchased their tested flavonoids (purity not mentioned), and both flavonoids belong to the same flavonoid classification (flavonol), the concentration required to achieve the anti-cancer effects varied. More efforts are required to standardize the isolation and purification method, recommend dosage required for each cancer, and understand the effects of flavonoids bioavailability, solubility and metabolic alteration on the observed anti-cancer effects.

\subsection{Possible Synergistic Effects of Flavonoids?}

While the type and concentration of flavonoids consumed are critical to observe the possible biological activities, selecting the ones that trigger multiple metabolic pathways may be improve the pathogenesis of GI cancer. For instance, genistein, an isoflavone, triggers four different pathways in cancer such as the extrinsic apoptotic pathway by activating caspase 3 activates, cellular invasion by enhancing the expression of E- cadherin, 
cellular proliferation by an unknown mechanism, and cellular inflammation by reducing nuclear translocation of NF- $\mathrm{kB}$. On the other hand, baicalein, delphinidin and daidzein act on more specific pathways (Figures 7-9). By combining these four flavonoids together, could their anti-cancer effects improve as they targeted multiple pathways? Moreover, could they complement each other pathway-wise? Currently, these are only suggestions that need further research to support and avoid possible side effects. Also, more research is needed to investigate the mechanism of hesperidin, a flavanone, which triggers both intrinsic and extrinsic apoptotic pathways.

\section{Conclusions}

Flavonoids ubiquitously found in fruits and vegetables are metabolized in the body by gut enzymes and pose a potential therapeutic and preventive tool to reduce the risk of GI cancer. Generally, signature bacteria in the gut with specific enzymatic activities that produce flavonoid metabolites could enhance the anticancer effects by triggering multiple pathways. Despite that, more research is required to identify the major enzymes, the impact of current treatments on enzymatic activities and the appropriate flavonoids dose required to achieve the observed anticancer effects. Additionally, clinical trials assessing those benefits are needed to estimate the potential of using flavonoids in a clinical setting against cancer.

Author Contributions: Conceptualization, R.K.A.-I. and D.B.; literature review and resources, R.K.A.I., A.L. and P.K.; writing-original draft preparation, R.K.A.-I., A.L. and P.K.; writing-review and editing, D.B.; figure preparation and editing, R.K.A.-I. and D.B.; visualization, R.K.A.-I. and D.B.; supervision, D.B.; project administration, D.B.; funding acquisition, D.B. All authors reviewed the results and approved the final version of the manuscript.

Funding: This work was supported by a National Priorities Research Program grant (NPRP 11S-1214170101; awarded to Dietrich Büsselberg, June 2019-Current) from the Qatar National Research Fund (QNRF, a member of Qatar Foundation). The statements made herein are solely the responsibility of the authors. The publication costs of this article were founded by Qatar Foundation through the Weill Cornell Medicine-Qatar Biomedical Research Program-Mamtani Lab.

Conflicts of Interest: The authors declare no conflict of interest.

$\begin{array}{ll}\text { Abbreviations } \\ \text { GI } & \text { gastrointestinal } \\ \text { CRC } & \text { colorectal cancer } \\ \text { GC } & \text { gastric cancer } \\ \text { EC } & \text { esophageal cancer } \\ \text { HCC } & \text { hepatocellular carcinoma } \\ \text { PC } & \text { pancreatic cancer } \\ \text { PI3K } & \text { phosphatidylinositol 3-kinase } \\ \text { AKT } & \text { protein kinase B } \\ \text { NF-kB } & \text { nuclear factor kappa } \\ \text { EMT } & \text { epithelial-mesenchymal transition } \\ \text { E. ramulus } & \text { Eubacterium ramulus } \\ \text { HLPC } & \text { High-performance liquid chromatography } \\ \text { FISH } & \text { Fluorescence in situ hybridization } \\ \text { PMFs } & \text { polymethoxyflavones } \\ \text { BCL-2 } & \text { B-cell lymphoma 2 } \\ \text { PTEN } & \text { Phosphatase and tensin homolog } \\ \text { RON } & \text { d'origine Nantais } \\ \text { ERK } & \text { extracellular-signal-regulated kinase } \\ \text { ROS } & \text { Reactive oxygen species } \\ \text { PPAR- } \gamma & \text { Peroxisome proliferator-activated receptor gamma } \\ \end{array}$




$\begin{array}{ll}\text { Sp1 } & \text { specificity protein } 1 \\ \text { COX-2 } & \text { Prostaglandin-endoperoxide synthase 2 } \\ \text { SOD } & \text { Superoxide dismutase } \\ \text { mTOR } & \text { Mechanistic target of rapamycin } \\ \text { Egr1 } & \text { Early growth response 1 } \\ \text { FMT } & \text { Fecal microbiota transplant } \\ \text { MEK } & \text { Mitogen-activated protein kinase kinase } \\ \text { TCF } & \text { T cell factor } \\ \text { IKK } & \text { IKB kinase }\end{array}$

\section{References}

1. Hassanzade, J.; Molavi, E.V.H.; Farahmand, M.; Rajaiifard, A.R. Incidence and Mortality Rate of Common Gastrointestinal Cancers in South of Iran, a Population Based Study. Iran. J. Cancer Prev. 2011, 4, 163-169. [PubMed]

2. Abotaleb, M.; Samuel, S.M.; Varghese, E.; Varghese, S.; Kubatka, P.; Liskova, A.; Busselberg, D. Flavonoids in Cancer and Apoptosis. Cancers 2018, 11, 28. [CrossRef] [PubMed]

3. Rozen, P. Cancer of the gastrointestinal tract: Early detection or early prevention? Eur. J. Cancer Prev. 2004, 13, 71-75. [CrossRef] [PubMed]

4. Pourhoseingholi, M.A.; Vahedi, M.; Baghestani, A.R. Burden of gastrointestinal cancer in Asia; an overview. Gastroenterol. Hepatol. Bed Bench. 2015, 8, 19-27.

5. Zali, H.; Rezaei-Tavirani, M.; Azodi, M. Gastric cancer: Prevention, risk factors and treatment. Gastroenterol. Hepatol. Bed Bench. 2011, 4, 175-185.

6. Han, C.J.; Reding, K.; Cooper, B.A.; Paul, S.M.; Conley, Y.P.; Hammer, M.; Miaskowski, C. Symptom Clusters in Patients With Gastrointestinal Cancers Using Different Dimensions of the Symptom Experience. J. Pain Symptom Manag. 2019, 58, $224-234$. [CrossRef]

7. Correa, P. Gastric cancer: Overview. Gastroenterol. Clin N. Am. 2020, 42, 211-217. [CrossRef]

8. Igney, F.H.; Krammer, P.H. Death and anti-death: Tumour resistance to apoptosis. Nat. Rev. Cancer 2002, 2, 277-288. [CrossRef]

9. Qiao, L.; Wong, B.C. Targeting apoptosis as an approach for gastrointestinal cancer therapy. Drug Resist. Updat. 2009, 12, 55-64. [CrossRef]

10. Panche, A.N.; Diwan, A.D.; Chandra, S.R. Flavonoids: An overview. J. Nutr. Sci. 2016, 5, 1-15. [CrossRef]

11. Kozlowska, A.; Szostak-Wegierek, D. Flavonoids-food sources and health benefits. Rocz. Panstw. Zakl. Hig. 2014, 65, 79-85.

12. Al-Ishaq, R.K.; Abotaleb, M.; Kubatka, P.; Kajo, K.; Busselberg, D. Flavonoids and Their Anti-Diabetic Effects: Cellular Mechanisms and Effects to Improve Blood Sugar Levels. Biomolecules 2019, 9, 430. [CrossRef]

13. Romagnolo, D.F.; Selmin, O.I. Flavonoids and cancer prevention: A review of the evidence. J. Nutr. Gerontol. Geriatr. 2012, 31, 206-238. [CrossRef]

14. Jun, S.; Shin, S.; Joung, H. Estimation of dietary flavonoid intake and major food sources of Korean adults. Br. J. Nutr. 2016, 115, 480-489. [CrossRef]

15. Yu, Y.; Jing, X.; Li, H.; Zhao, X.; Wang, D. Soy isoflavone consumption and colorectal cancer risk: A systematic review and meta-analysis. Sci. Rep. 2016, 6, 25939. [CrossRef]

16. Molina-Montes, E.; Sanchez, M.J.; Zamora-Ros, R.; Bueno-de-Mesquita, H.B.; Wark, P.A.; Obon-Santacana, M.; Duell, E.J. Flavonoid and lignan intake and pancreatic cancer risk in the European prospective investigation into cancer and nutrition cohort. Int. J. Cancer 2016, 139, 1480-1492. [CrossRef]

17. Xu, M.; Chen, Y.M.; Huang, J.; Fang, Y.J.; Huang, W.Q.; Yan, B.; Zhang, C.X. Flavonoid intake from vegetables and fruits is inversely associated with colorectal cancer risk: A case-control study in China. Br. J. Nutr. 2016, 116, 1275-1287. [CrossRef]

18. Louis, P.; Hold, G.L.; Flint, H.J. The gut microbiota, bacterial metabolites and colorectal cancer. Nat. Rev. Microbiol. 2014, 12, 661-672. [CrossRef]

19. Chen, Z.; Zheng, S.; Li, L.; Jiang, H. Metabolism of flavonoids in human: A comprehensive review. Curr. Drug Metab. 2014, 15, 48-61. [CrossRef]

20. Duda-Chodak, A.; Tarko, T.; Satora, P.; Sroka, P. Interaction of dietary compounds, especially polyphenols, with the intestinal microbiota: A review. Eur. J. Nutr. 2015, 54, 325-341. [CrossRef]

21. Pei, R.; Liu, X.; Bolling, B. Flavonoids and gut health. Curr. Opin. Biotechnol. 2020, 61, 153-159. [CrossRef]

22. Murota, K.; Nakamura, Y.; Uehara, M. Flavonoid metabolism: The interaction of metabolites and gut microbiota. Biosci. Biotechnol. Biochem. 2018, 82, 600-610. [CrossRef]

23. Kawabata, K.; Yoshioka, Y.; Terao, J. Role of Intestinal Microbiota in the Bioavailability and Physiological Functions of Dietary Polyphenols. Molecules 2019, 24, 370. [CrossRef]

24. Del Rio, D.; Calani, L.; Scazzina, F.; Jechiu, L.; Cordero, C.; Brighenti, F. Bioavailability of catechins from ready-to-drink tea. Nutrition 2010, 26, 528-533. [CrossRef]

25. Braune, A.; Engst, W.; Elsinghorst, P.W.; Furtmann, N.; Bajorath, J.; Gutschow, M.; Blaut, M. Chalcone Isomerase from Eubacterium ramulus Catalyzes the Ring Contraction of Flavanonols. J. Bacteriol. 2016, 198, 2965-2974. [CrossRef] 
26. Simmering, R.; Pforte, H.; Jacobasch, G.; Blaut, M. The growth of the flavonoid-degrading intestinal bacterium, Eubacterium ramulus, is stimulated by dietary flavonoids in vivo. FEMS Microbiol. Ecol. 2002, 40, 243-248. [CrossRef]

27. Curro, D. The role of gut microbiota in the modulation of drug action: A focus on some clinically significant issues. Expert Rev. Clin Pharm. 2018, 11, 171-183. [CrossRef]

28. Luca, S.V.; Macovei, I.; Bujor, A.; Miron, A.; Skalicka-Wozniak, K.; Aprotosoaie, A.C.; Trifan, A. Bioactivity of dietary polyphenols: The role of metabolites. Crit. Rev. Food Sci. Nutr. 2020, 60, 626-659. [CrossRef]

29. Zamora-Ros, R.; Knaze, V.; Rothwell, J.A.; Hemon, B.; Moskal, A.; Overvad, K.; Scalbert, A. Dietary polyphenol intake in Europe: The European Prospective Investigation into Cancer and Nutrition (EPIC) study. Eur. J. Nutr. 2016, 55, 1359-1375. [CrossRef]

30. Ghorbani, A. Mechanisms of antidiabetic effects of flavonoid rutin. Biomed Pharm. 2017, 96, 305-312. [CrossRef]

31. Shin, N.R.; Moon, J.S.; Shin, S.Y.; Li, L.; Lee, Y.B.; Kim, T.J.; Han, N.S. Isolation and characterization of human intestinal Enterococcus avium EFEL009 converting rutin to quercetin. Lett. Appl. Microbiol. 2016, 62, 68-74. [CrossRef] [PubMed]

32. Riva, A.; Kolimar, D.; Spittler, A.; Wisgrill, L.; Herbold, C.W.; Abranko, L.; Berry, D. Conversion of Rutin, a Prevalent Dietary Flavonol, by the Human Gut Microbiota. Front. Microbiol. 2020, 11, 585428. [CrossRef] [PubMed]

33. Mazzeo, M.F.; Lippolis, R.; Sorrentino, A.; Liberti, S.; Fragnito, F.; Siciliano, R.A. Lactobacillus acidophilus-Rutin Interplay Investigated by Proteomics. PLoS ONE 2015, 10, e0142376. [CrossRef] [PubMed]

34. Khan, N.; Syed, D.N.; Ahmad, N.; Mukhtar, H. Fisetin: A dietary antioxidant for health promotion. Antioxid. Redox Signal. 2013, 19, 151-162. [CrossRef]

35. Kawabata, K.; Sugiyama, Y.; Sakano, T.; Ohigashi, H. Flavonols enhanced production of anti-inflammatory substance(s) by Bifidobacterium adolescentis: Prebiotic actions of galangin, quercetin, and fisetin. Biofactors 2013, 39, 422-429. [CrossRef]

36. Imran, M.; Salehi, B.; Sharifi-Rad, J.; Aslam Gondal, T.; Saeed, F.; Imran, A.; Estevinho, L.M. Kaempferol: A Key Emphasis to Its Anticancer Potential. Molecules 2019, 24, 2277. [CrossRef]

37. Crespy, V.; Morand, C.; Besson, C.; Cotelle, N.; Vezin, H.; Demigne, C.; Remesy, C. The splanchnic metabolism of flavonoids highly differed according to the nature of the compound. Am. J. Physiol. Gastrointest. Liver Physiol. 2003, 284, G980-G988. [CrossRef]

38. Vollmer, M.; Esders, S.; Farquharson, F.M.; Neugart, S.; Duncan, S.H.; Schreiner, M.; Rohn, S. Mutual Interaction of Phenolic Compounds and Microbiota: Metabolism of Complex Phenolic Apigenin-C- and Kaempferol-O-Derivatives by Human Fecal Samples. J. Agric. Food Chem. 2018, 66, 485-497. [CrossRef]

39. Shimojo, Y.; Ozawa, Y.; Toda, T.; Toda, T.; Igami, K.; Shimizu, T. Probiotic Lactobacillus paracasei A221 improves the functionality and bioavailability of kaempferol-glucoside in kale by its glucosidase activity. Sci. Rep. 2018, 8, 9239. [CrossRef]

40. Salehi, B.; Machin, L.; Monzote, L.; Sharifi-Rad, J.; Ezzat, S.M.; Salem, M.A.; Cho, W.C. Therapeutic Potential of Quercetin: New Insights and Perspectives for Human Health. ACS Omega. 2020, 5, 11849-11872. [CrossRef]

41. Guo, Y.; Bruno, R.S. Endogenous and exogenous mediators of quercetin bioavailability. J. Nutr. Biochem. 2015, 26, 201-210. [CrossRef]

42. Bischoff, S.C. Quercetin: Potentials in the prevention and therapy of disease. Curr. Opin. Clin Nutr. Metab. Care 2008, 11, 733-740. [CrossRef]

43. Najmanova, I.; Pourova, J.; Voprsalova, M.; Pilarova, V.; Semecky, V.; Novakova, L.; Mladenka, P. Flavonoid metabolite 3-(3hydroxyphenyl)propionic acid formed by human microflora decreases arterial blood pressure in rats. Mol. Nutr. Food Res. 2016, 60, 981-991. [CrossRef]

44. Santangelo, R.; Silvestrini, A.; Mancuso, C. Ginsenosides, catechins, quercetin and gut microbiota: Current evidence of challenging interactions. Food Chem. Toxicol. 2019, 123, 42-49. [CrossRef]

45. Tamura, M.; Hoshi, C.; Kobori, M.; Takahashi, S.; Tomita, J.; Nishimura, M.; Nishihira, J. Quercetin metabolism by fecal microbiota from healthy elderly human subjects. PLoS ONE 2017, 12, e0188271. [CrossRef]

46. Vinayagam, R.; Xu, B. Antidiabetic properties of dietary flavonoids: Acellular mechanism review. Nutr. Metab. Lond. 2015, 12, 60. [CrossRef]

47. Du, L.Y.; Zhao, M.; Tao, J.H.; Qian, D.W.; Jiang, S.; Shang, E.X.; Duan, J.A. The Metabolic Profiling of Isorhamnetin-3-ONeohesperidoside Produced by Human Intestinal Flora Employing UPLC-Q-TOF/MS. J. Chromatogr. Sci. 2017, 55, 243-250. [CrossRef]

48. Parhiz, H.; Roohbakhsh, A.; Soltani, F.; Rezaee, R.; Iranshahi, M. Antioxidant and anti-inflammatory properties of the citrus flavonoids hesperidin and hesperetin: An updated review of their molecular mechanisms and experimental models. Phyther. Res. 2015, 29, 323-331. [CrossRef]

49. Williamson, G. The role of polyphenols in modern nutrition. Nutr. Bull. 2017, 42, 226-235. [CrossRef]

50. Garg, A.; Garg, S.; Zaneveld, L.J.; Singla, A.K. Chemistry and pharmacology of the citrus bioflavonoid hesperidin. Phyther. Res. 2001, 15, 655-669. [CrossRef]

51. Estruel-Amades, S.; Massot-Cladera, M.; Perez-Cano, F.J.; Franch, A.; Castell, M.; Camps-Bossacoma, M. Hesperidin Effects on Gut Microbiota and Gut-Associated Lymphoid Tissue in Healthy Rats. Nutrients 2019, 11, 324. [CrossRef] [PubMed]

52. Chen, T.; Wu, H.; He, Y.; Pan, W.; Yan, Z.; Liao, Y.; Yao, H. Simultaneously Quantitative Analysis of Naringin and Its Major Human Gut Microbial Metabolites Naringenin and 3-(4'-Hydroxyphenyl) Propanoic Acid via Stable Isotope Deuterium-Labeling Coupled with RRLC-MS/MS Method. Molecules 2019, 24, 4287. [CrossRef] [PubMed] 
53. Feng, T.; Wang, K.; Liu, F.; Ye, R.; Zhu, X.; Zhuang, H.; Xu, Z. Structural characterization and bioavailability of ternary nanoparticles consisting of amylose, $\alpha \beta$-linoleic acid and _-lactoglobulin complexed with naringin. Int. J. Biol. Macromol. 2017, 99, 365-374. [CrossRef] [PubMed]

54. Firrman, J.; Liu, L.; Argoty, G.A.; Zhang, L.; Tomasula, P.; Wang, M.; Xiao, W. Analysis of Temporal Changes in Growth and Gene Expression for Commensal Gut Microbes in Response to the Polyphenol Naringenin. Microbiol. Insights. 2018, 11. [CrossRef]

55. Islam, A.; Islam, M.S.; Rahman, M.K.; Uddin, M.N.; Akanda, M.R. The pharmacological and biological roles of eriodictyol. Arch. Pharm. Res. 2020, 43, 582-592. [CrossRef]

56. Braune, A.; Blaut, M. Bacterial species involved in the conversion of dietary flavonoids in the human gut. Gut. Microbes. 2016, 7, 216-234. [CrossRef]

57. Miyake, Y.; Yamamoto, K.; Osawa, T. Metabolism of Antioxidant in Lemon Fruit (Citrus limon BURM. f.) by Human Intestinal Bacteria. J. Agric. Food Chem. 1997, 45, 3738-3742. [CrossRef]

58. Li, H.Q.; Luo, Y.; Qiao, C.H. The mechanisms of anticancer agents by genistein and synthetic derivatives of isoflavone. Mini. Rev. Med. Chem. 2012, 12, 350-362.

59. Matthies, A.; Clavel, T.; Gutschow, M.; Engst, W.; Haller, D.; Blaut, M.; Braune, A. Conversion of daidzein and genistein by an anaerobic bacterium newly isolated from the mouse intestine. Appl. Environ. Microbiol. 2008, 74, 4847-4852. [CrossRef]

60. Wang, X.L.; Shin, K.H.; Hur, H.G.; Kim, S.I. Enhanced biosynthesis of dihydrodaidzein and dihydrogenistein by a newly isolated bovine rumen anaerobic bacterium. J. Biotechnol. 2005, 115, 261-269. [CrossRef]

61. Heinonen, S.; Wahala, K.; Adlercreutz, H. Identification of isoflavone metabolites dihydrodaidzein, dihydrogenistein, 6'-OH$\mathrm{O}-\mathrm{dma}$, and cis-4-OH-equol in human urine by gas chromatography-mass spectroscopy using authentic reference compounds. Anal. Biochem. 1999, 274, 211-219. [CrossRef]

62. Das, D.; Sarkar, S.; Bordoloi, J.; Wann, S.B.; Kalita, J.; Manna, P. Daidzein, its effects on impaired glucose and lipid metabolism and vascular inflammation associated with type 2 diabetes. Biofactors 2018, 44, 407-417. [CrossRef]

63. Maddalena, R.; Alberto, A.; Roncaglia, L.; Alan, L.; Stefano, R. Dietary isoflavones and intestinal microbiota. In Isoflavones Biosynthesis, Occurence and Health Effects; Thompson, J., Ed.; Nova Science Publishers: New York, NY, USA, 2010 ; pp. 137-161.

64. Wang, X.L.; Kim, H.J.; Kang, S.I.; Kim, S.I.; Hur, H.G. Production of phytoestrogen S-equol from daidzein in mixed culture of two anaerobic bacteria. Arch. Microbiol. 2007, 187, 155-160. [CrossRef]

65. Akkarachiyasit, S.; Charoenlertkul, P.; Yibchok-Anun, S.; Adisakwattana, S. Inhibitory activities of cyanidin and its glycosides and synergistic effect with acarbose against intestinal alpha-glucosidase and pancreatic alpha-amylase. Int. J. Mol. Sci. 2010, 11, 3387-3396. [CrossRef]

66. McGhie, T.K.; Walton, M.C. The bioavailability and absorption of anthocyanins: Towards a better understanding. Mol. Nutr. Food Res. 2007, 51, 702-713. [CrossRef]

67. Hanske, L.; Engst, W.; Loh, G.; Sczesny, S.; Blaut, M.; Braune, A. Contribution of gut bacteria to the metabolism of cyanidin 3-glucoside in human microbiota-associated rats. Br. J. Nutr. 2013, 109, 1433-1441. [CrossRef]

68. Ko, H.; Jeong, M.H.; Jeon, H.; Sung, G.J.; So, Y.; Kim, I.; Choi, K.C. Delphinidin sensitizes prostate cancer cells to TRAIL-induced apoptosis, by inducing DR5 and causing caspase-mediated HDAC3 cleavage. Oncotarget 2015, 6, 9970-9984. [CrossRef]

69. Lim, W.; Song, G. Inhibitory effects of delphinidin on the proliferation of ovarian cancer cells via PI3K/AKT and ERK $1 / 2$ MAPK signal transduction. Oncol. Lett. 2017, 14, 810-818. [CrossRef]

70. Eker, M.E.; Aaby, K.; Budic-Leto, I.; Brncic, S.R.; El, S.N.; Karakaya, S.; Pascual-Teresa, S. A Review of Factors Affecting Anthocyanin Bioavailability: Possible Implications for the Inter-Individual Variability. Foods 2019, 9, 2. [CrossRef]

71. Aura, A.M.; Martin-Lopez, P.; O’Leary, K.A.; Williamson, G.; Oksman-Caldentey, K.M.; Poutanen, K.; Santos-Buelga, C. In vitro metabolism of anthocyanins by human gut microflora. Eur. J. Nutr. 2005, 44, 133-142. [CrossRef]

72. Flores, G.; Costabile, A.; Klee, A.; Guergoletto, K.; Gibson, G. In vitro fermentation of anthocyanins encapsulated with cyclodextrins: Release, metabolism and influence on gut microbiota growth. J. Funct. Foods 2015, 16, 10. [CrossRef]

73. Mazza, G. Compositional and Functional Properties of Saskatoon Berry and Blueberry. Int. J. Fruit Sci. 2006, 5, 101-120. [CrossRef]

74. Mattioli, R.; Francioso, A.; Mosca, L.; Silva, P. Anthocyanins: A Comprehensive Review of Their Chemical Properties and Health Effects on Cardiovascular and Neurodegenerative Diseases. Molecules 2020, 25, 3809. [CrossRef]

75. Sowndhararajan, K.; Deepa, P.; Kim, M.; Park, S.J.; Kim, S. Baicalein as a potent neuroprotective agent: A review. Biomed. Pharm. 2017, 95, 1021-1032. [CrossRef]

76. Li-Weber, M. New therapeutic aspects of flavones: The anticancer properties of Scutellaria and its main active constituents wogonin, baicalein and baicalin. Cancer Treat. Rev. 2009, 35, 57-68. [CrossRef] [PubMed]

77. Noh, K.; Kang, Y.; Nepal, M.R.; Jeong, K.S.; Oh, D.G.; Kang, M.J.; Jeong, T.C. Role of Intestinal Microbiota in Baicalin-Induced Drug Interaction and Its Pharmacokinetics. Molecules 2016, 21, 337. [CrossRef]

78. Wang, C.Z.; Zhang, C.F.; Chen, L.; Anderson, S.; Lu, F.; Yuan, C.S. Colon cancer chemopreventive effects of baicalein, an active enteric microbiome metabolite from baicalin. Int. J. Oncol. 2015, 47, 1749-1758. [CrossRef]

79. Feldo, M.; Wozniak, M.; Wojciak-Kosior, M.; Sowa, I.; Kot-Wasik, A.; Aszyk, J.; Bogucka-Kocka, A. Influence of Diosmin Treatment on the Level of Oxidative Stress Markers in Patients with Chronic Venous Insufficiency. Oxid. Med. Cell Longev. 2018, $2018,2561705$. [CrossRef]

80. Zhao, Y.; Zhang, J.; Liu, W. Diosmin Regulates Oxidative Stress and Inflammatory Marker Levels in N-Methyl-N-NitrosoureaInduced Gastric Carcinogenesis in Rats. J. Env. Pathol. Toxicol. Oncol. 2020, 39, 375-384. [CrossRef] 
81. Patel, K.; Gadewar, M.; Tahilyani, V.; Patel, D.K. A review on pharmacological and analytical aspects of diosmetin: A concise report. Chin. J. Integr. Med. 2013, 19, 792-800. [CrossRef]

82. Russo, R.; Chandradhara, D.; De Tommasi, N. Comparative Bioavailability of Two Diosmin Formulations after Oral Administration to Healthy Volunteers. Molecules 2018, 23, 2174. [CrossRef] [PubMed]

83. Salehi, B.; Venditti, A.; Sharifi-Rad, M.; Kregiel, D.; Sharifi-Rad, J.; Durazzo, A.; Martins, N. The Therapeutic Potential of Apigenin. Int. J. Mol. Sci. 2019, 20, 1305. [CrossRef] [PubMed]

84. Sharma, A.; Kaur, M.; Katnoria, J.K.; Nagpal, A.K. Polyphenols in Food: Cancer Prevention and Apoptosis Induction. Curr. Med. Chem. 2018, 25, 4740-4757. [CrossRef] [PubMed]

85. Wang, M.; Firrman, J.; Liu, L.; Yam, K. A Review on Flavonoid Apigenin: Dietary Intake, ADME, Antimicrobial Effects, and Interactions with Human Gut Microbiota. Biomed. Res. Int. 2019, 2019, 7010467. [CrossRef]

86. Steed, L.; Christophi, G.P.; Kaiko, G.E. The microbial metabolite desaminotyrosine protects from influenza through type I interferon. Science 2017, 357, 498-502. [CrossRef]

87. Ashrafizadeh, M.; Ahmadi, Z.; Mohammadinejad, R.; Ghasemipour Afshar, E. Tangeretin: A mechanistic review of its pharmacological and therapeutic effects. J. Basic Clin Physiol. Pharm. 2020, 31, 4. [CrossRef]

88. Chen, J.; Wang, Y.; Zhu, T.; Yang, S.; Cao, J.; Li, X.; Sun, C. Beneficial Regulatory Effects of Polymethoxyflavone-Rich Fraction from Ougan (Citrus reticulata cv. Suavissima) Fruit on Gut Microbiota and Identification of Its Intestinal Metabolites in Mice. Antioxidants 2020, 9, 831. [CrossRef]

89. Enomoto, R.; Suzuki, C.; Koshiba, C.; Nishino, T.; Nakayama, M.; Hirano, H.; Lee, E. Wogonin prevents immunosuppressive action but not anti-inflammatory effect induced by glucocorticoid. Ann. N. Y. Acad. Sci. 2007, 1095, 412-417. [CrossRef]

90. Seong, R.K.; Kim, J.A.; Shin, O.S. Wogonin, a flavonoid isolated from Scutellaria baicalensis, has anti-viral activities against influenza infection via modulation of AMPK pathways. Acta. Virol. 2018, 62, 78-85. [CrossRef]

91. Xing, S.H.; Wang, M.Y.; Peng, Y.; Chen, D.F.; Li, X.B. Simulated gastrointestinal tract metabolism and pharmacological activities of water extract of Scutellaria baicalensis roots. J. Ethnopharmacol. 2014, 152, 183-189. [CrossRef]

92. Xing, S.; Wang, M.; Peng, Y.; Li, X. Effects of Intestinal Microecology on Metabolism and Pharmacokinetics of Oral Wogonoside and Baicalin. Nat. Prod. Commun. 2017, 12, 509-514. [CrossRef]

93. Farkhondeh, T.; Abedi, F.; Samarghandian, S. Chrysin attenuates inflammatory and metabolic disorder indices in aged male rat. Biomed Pharm. 2019, 109, 1120-1125. [CrossRef]

94. Bolca, S.; Van de Wiele, T.; Possemiers, S. Gut metabotypes govern health effects of dietary polyphenols. Curr. Opin. Biotechnol. 2013, 24, 220-225. [CrossRef]

95. Yang, G.; Hong, S.; Yang, P.; Sun, Y.; Wang, Y.; Zhang, P.; Gu, Y. Discovery of an ene-reductase for initiating flavone and flavonol catabolism in gut bacteria. Nat. Commun. 2021, 12, 790. [CrossRef]

96. Pollastri, S.; Tattini, M. Flavonols: Old compounds for old roles. Ann. Bot. 2011, 108, 1225-1233. [CrossRef]

97. Najmanova, I.; Voprsalova, M.; Saso, L.; Mladenka, P. The pharmacokinetics of flavanones. Crit. Rev. Food Sci. Nutr. 2020, 60, 3155-3171. [CrossRef]

98. Pabich, M.; Materska, M. Biological Effect of Soy Isoflavones in the Prevention of Civilization Diseases. Nutrients 2019, 11, 1660. [CrossRef]

99. Guimarães, R.M.; Silva, T.E.; Lemes, A.C.; Boldrin, M.C.F.; Silva Pereira, M.A.; Silva, F.G.; Egea, M.B. Okara: A soybean by-product as an alternative to enrich vegetable paste. LWT Food Sci. Technol. 2018, 92, 593-599. [CrossRef]

100. Khoo, H.E.; Azlan, A.; Tang, S.T.; Lim, S.M. Anthocyanidins and anthocyanins: Colored pigments as food, pharmaceutical ingredients, and the potential health benefits. Food Nutr. Res. 2017, 61, 1361779. [CrossRef]

101. Lin, B.W.; Gong, C.C.; Song, H.F.; Cui, Y.Y. Effects of anthocyanins on the prevention and treatment of cancer. Br. J. Pharmacol. 2017, 174, 1226-1243. [CrossRef]

102. Hostetler, G.L.; Ralston, R.A.; Schwartz, S.J. Flavones: Food Sources, Bioavailability, Metabolism, and Bioactivity. Adv. Nutr. 2017, 8, 423-435. [CrossRef]

103. Martens, S.; Mithofer, A. Flavones and flavone synthases. Phytochemistry 2005, 66, 2399-2407. [CrossRef]

104. Al-Ishaq, R.K.; Overy, A.J.; Busselberg, D. Phytochemicals and Gastrointestinal Cancer: Cellular Mechanisms and Effects to Change Cancer Progression. Biomolecules 2020, 10, 105. [CrossRef]

105. Liskova, A.; Koklesova, L.; Samec, M.; Smejkal, K.; Samuel, S.M.; Varghese, E.; Kubatka, P. Flavonoids in Cancer Metastasis. Cancers Basel 2020, 12, 1498. [CrossRef]

106. Koklesova, L.; Liskova, A.; Samec, M.; Zhai, K.; Abotaleb, M.; Ashrafizadeh, M.; Kubatka, P. Carotenoids in Cancer MetastasisStatus Quo and Outlook. Biomolecules 2020, 10, 1653. [CrossRef]

107. Ben Sghaier, M.; Pagano, A.; Mousslim, M.; Ammari, Y.; Kovacic, H.; Luis, J. Rutin inhibits proliferation, attenuates superoxide production and decreases adhesion and migration of human cancerous cells. Biomed Pharm. 2016, 84, 1972-1978. [CrossRef]

108. Yang, K.; Lamprecht, S.A.; Liu, Y.; Shinozaki, H.; Fan, K.; Leung, D.; Lipkin, M. Chemoprevention studies of the flavonoids quercetin and rutin in normal and azoxymethane-treated mouse colon. Carcinogenesis 2000, 21, 1655-1660. [CrossRef]

109. Fideles, L.S.; de Miranda, J.A.L.; Martins, C.D.S.; Barbosa, M.L.L.; Pimenta, H.B.; Pimentel, P.V.S.; Cerqueira, G.S. Role of Rutin in 5-Fluorouracil-Induced Intestinal Mucositis: Prevention of Histological Damage and Reduction of Inflammation and Oxidative Stress. Molecules 2020, 25, 2786. [CrossRef] [PubMed] 
110. Youns, M.; Abdel Halim Hegazy, W. The Natural Flavonoid Fisetin Inhibits Cellular Proliferation of Hepatic, Colorectal, and Pancreatic Cancer Cells through Modulation of Multiple Signaling Pathways. PLoS ONE 2017, 12, e0169335. [CrossRef]

111. Yang, L.; Li, H.; Yang, M.; Zhang, W.; Li, M.; Xu, Y.; Guo, S. Exploration in the Mechanism of Kaempferol for the Treatment of Gastric Cancer Based on Network Pharmacology. Biomed Res. Int. 2020, 2020, 5891016. [CrossRef]

112. Song, H.; Bao, J.; Wei, Y.; Chen, Y.; Mao, X.; Li, J.; Xue, Y. Kaempferol inhibits gastric cancer tumor growth: An in vitro and in vivo study. Oncol. Rep. 2015, 33, 868-874. [CrossRef] [PubMed]

113. Wang, K.; Liu, R.; Li, J.; Mao, J.; Lei, Y.; Wu, J.; Wei, Y. Quercetin induces protective autophagy in gastric cancer cells: Involvement of Akt-mTOR- and hypoxia-induced factor 1alpha-mediated signaling. Autophagy 2011, 7, 966-978. [CrossRef] [PubMed]

114. Shen, X.; Si, Y.; Wang, Z.; Wang, J.; Guo, Y.; Zhang, X. Quercetin inhibits the growth of human gastric cancer stem cells by inducing mitochondrial-dependent apoptosis through the inhibition of PI3K/Akt signaling. Int. J. Mol. Med. 2016, 38, 619-626. [CrossRef]

115. Ramachandran, L.; Manu, K.A.; Shanmugam, M.K.; Li, F.; Siveen, K.S.; Vali, S.; Sethi, G. Isorhamnetin inhibits proliferation and invasion and induces apoptosis through the modulation of peroxisome proliferator-activated receptor gamma activation pathway in gastric cancer. J. Biol. Chem. 2012, 287, 38028-38040. [CrossRef]

116. Antunes-Ricardo, M.; Moreno-Garcia, B.E.; Gutierrez-Uribe, J.A.; Araiz-Hernandez, D.; Alvarez, M.M.; Serna-Saldivar, S.O. Induction of apoptosis in colon cancer cells treated with isorhamnetin glycosides from Opuntia ficus-indica pads. Plant Foods Hum. Nutr. 2014, 69, 331-336. [CrossRef]

117. Chen, R.; Zhang, L. Morin inhibits colorectal tumor growth through inhibition of NF-kappaB signaling pathway. Immunopharmacol. Immunotoxicol. 2019, 41, 622-629. [CrossRef]

118. Sithara, T.; Arun, K.B.; Syama, H.P.; Reshmitha, T.R.; Nisha, P. Morin Inhibits Proliferation of SW480 Colorectal Cancer Cells by Inducing Apoptosis Mediated by Reactive Oxygen Species Formation and Uncoupling of Warburg Effect. Front. Pharmacol. 2017, 8, 640. [CrossRef]

119. Zhang, J.; Wu, D.; Vikash, S.J.; Wang, J.; Yi, J.; Dong, W. Hesperetin Induces the Apoptosis of Gastric Cancer Cells via Activating Mitochondrial Pathway by Increasing Reactive Oxygen Species. Dig. Dis. Sci. 2015, 60, 2985-2995. [CrossRef]

120. He, P.; Ma, J.; Liu, Y.; Deng, H.; Dong, W. Hesperetin Promotes Cisplatin-Induced Apoptosis of Gastric Cancer In Vitro and In Vivo by Upregulating PTEN Expression. Front. Pharm. 2020, 11, 1326. [CrossRef]

121. Bao, L.; Liu, F.; Guo, H.B.; Li, Y.; Tan, B.B.; Zhang, W.X.; Peng, Y.H. Naringenin inhibits proliferation, migration, and invasion as well as induces apoptosis of gastric cancer SGC7901 cell line by downregulation of AKT pathway. Tumour. Biol. 2016, 37, 11365-11374. [CrossRef]

122. Sequetto, P.L.; Oliveira, T.T.; Maldonado, I.R.; Augusto, L.E.; Mello, V.J.; Pizziolo, V.R.; Novaes, R.D. Naringin accelerates the regression of pre-neoplastic lesions and the colorectal structural reorganization in a murine model of chemical carcinogenesis. Food Chem. Toxicol. 2014, 64, 200-209. [CrossRef]

123. Mariyappan, P.; Kalaiyarasu, T.; Manju, V. Effect of eriodictyol on preneoplastic lesions, oxidative stress and bacterial enzymes in 1,2-dimethyl hydrazine-induced colon carcinogenesis. Toxicol. Res. Camb. 2017, 6, 678-692. [CrossRef]

124. Qin, J.; Chen, J.X.; Zhu, Z.; Teng, J.A. Genistein inhibits human colorectal cancer growth and suppresses miR-95, Akt and SGK1. Cell Physiol. Biochem. 2015, 35, 2069-2077. [CrossRef]

125. Yu, D.; Shin, H.S.; Lee, Y.S.; Lee, D.; Kim, S.; Lee, Y.C. Genistein attenuates cancer stem cell characteristics in gastric cancer through the downregulation of Gli1. Oncol. Rep. 2014, 31, 673-678. [CrossRef]

126. Zheng, W.; Sun, R.; Yang, L.; Zeng, X.; Xue, Y.; An, R. Daidzein inhibits choriocarcinoma proliferation by arresting cell cycle at G1 phase through suppressing ERK pathway in vitro and in vivo. Oncol. Rep. 2017, 38, 2518-2524. [CrossRef]

127. Shih, P.H.; Yeh, C.T.; Yen, G.C. Effects of anthocyanidin on the inhibition of proliferation and induction of apoptosis in human gastric adenocarcinoma cells. Food Chem. Toxicol. 2005, 43, 1557-1566. [CrossRef] [PubMed]

128. Huang, C.C.; Hung, C.H.; Hung, T.W. Dietary delphinidin inhibits human colorectal cancer metastasis associating with upregulation of miR-204-3p and suppression of the integrin/FAK axis. Sci. Rep. 2019, 9, 18954. [CrossRef] [PubMed]

129. Mazewski, C.; Kim, M.S.; Gonzalez de Mejia, E. Anthocyanins, delphinidin-3-O-glucoside and cyanidin-3-O-glucoside, inhibit immune checkpoints in human colorectal cancer cells in vitro and in silico. Sci. Rep. 2019, 9, 11560. [CrossRef]

130. Zeng, Q.; Zhang, Y.; Zhang, W.; Guo, Q. Baicalein suppresses the proliferation and invasiveness of colorectal cancer cells by inhibiting Snailinduced epithelialmesenchymal transition. Mol. Med. Rep. 2020, 21, 2544-2552.

131. Li, P.; Hu, J.; Shi, B.; Tie, J. Baicalein enhanced cisplatin sensitivity of gastric cancer cells by inducing cell apoptosis and autophagy via Akt/mTOR and Nrf2/Keap 1 pathway. Biochem. Biophys. Res. Commun. 2020, 531, 320-327. [CrossRef]

132. Pu, Y.; Zhang, T.; Wang, J.; Mao, Z.; Duan, B.; Long, Y.; Gao, Z. Luteolin exerts an anticancer effect on gastric cancer cells through multiple signaling pathways and regulating miRNAs. J. Cancer 2018, 9, 3669-3675. [CrossRef] [PubMed]

133. Ren, L.Q.; Li, Q.; Zhang, Y. Luteolin Suppresses the Proliferation of Gastric Cancer Cells and Acts in Synergy with Oxaliplatin. Biomed Res. Int. 2020, 2020, 9396512. [CrossRef] [PubMed]

134. Tanaka, T.; Makita, H.; Kawabata, K.; Mori, H.; Kakumoto, M.; Satoh, K.; Ogawa, H. Chemoprevention of azoxymethaneinduced rat colon carcinogenesis by the naturally occurring flavonoids, diosmin and hesperidin. Carcinogenesis 1997, 18, 957-965. [CrossRef]

135. Wang, B.; Zhao, X.H. Apigenin induces both intrinsic and extrinsic pathways of apoptosis in human colon carcinoma HCT-116 cells. Oncol. Rep. 2017, 37, 1132-1140. [CrossRef] 
136. Chen, J.; Chen, J.; Li, Z.; Liu, C.; Yin, L. The apoptotic effect of apigenin on human gastric carcinoma cells through mitochondrial signal pathway. Tumour. Biol. 2014, 35, 7719-7726. [CrossRef]

137. Zhang, X.; Zheng, L.; Sun, Y.; Wang, T.; Wang, B. Tangeretin enhances radiosensitivity and inhibits the radiation-induced epithelial-mesenchymal transition of gastric cancer cells. Oncol. Rep. 2015, 34, 302-310. [CrossRef]

138. Dong, Y.; Cao, A.; Shi, J.; Yin, P.; Wang, L.; Ji, G.; Wu, D. Tangeretin, a citrus polymethoxyflavonoid, induces apoptosis of human gastric cancer AGS cells through extrinsic and intrinsic signaling pathways. Oncol. Rep. 2014, 31, 1788-1794. [CrossRef]

139. Wang, T.; Gao, J.; Yu, J.; Shen, L. Synergistic inhibitory effect of wogonin and low-dose paclitaxel on gastric cancer cells and tumor xenografts. Chin. J. Cancer Res. 2013, 25, 505-513.

140. Feng, Q.; Wang, H.; Pang, J.; Ji, L.; Han, J.; Wang, Y.; Lu, L. Prevention of Wogonin on Colorectal Cancer Tumorigenesis by Regulating p53 Nuclear Translocation. Front. Pharmacol. 2018, 9, 1356. [CrossRef]

141. Bahadori, M.; Baharara, J.; Amini, E. Anticancer Properties of Chrysin on Colon Cancer Cells, In vitro and In vivo with Modulation of Caspase-3, -9, Bax and Sall4. Iran. J. Biotechnol. 2016, 14, 177-184. [CrossRef]

142. Debnath, J.; Baehrecke, E.H.; Kroemer, G. Does autophagy contribute to cell death? Autophagy 2005, 1, 66-74. [CrossRef] [PubMed]

143. Elmore, S. Apoptosis: A review of programmed cell death. Toxicol. Pathol. 2007, 35, 495-516. [CrossRef] [PubMed]

144. Danial, N.N.; Korsmeyer, S.J. Cell death: Critical control points. Cell 2004, 116, 205-219. [CrossRef]

145. Pfeffer, C.M.; Singh, A.T.K. Apoptosis: A Target for Anticancer Therapy. Int. J. Mol. Sci. 2018, 19, 448. [CrossRef]

146. Lopez, J.; Tait, S.W.G. Mitochondrial apoptosis: Killing cancer using the enemy within. Br. J. Cancer 2015, 112, 957-962. [CrossRef]

147. Ponte, L.G.S.; Pavan, I.C.B.; Mancini, M.C.S.; da Silva, L.G.S.; Morelli, A.P.; Severino, M.B.; Simabuco, F.M. The Hallmarks of Flavonoids in Cancer. Molecules 2021, 26, 2029. [CrossRef]

148. Sabarwal, A.; Agarwal, R.; Singh, R.P. Fisetin inhibits cellular proliferation and induces mitochondria-dependent apoptosis in human gastric cancer cells. Mol. Carcinog. 2017, 56, 499-514. [CrossRef]

149. Matson, J.P.; Cook, J.G. Cell cycle proliferation decisions: The impact of single cell analyses. FEBS J. 2017, 284, 362-375. [CrossRef]

150. Davis, C.D.; Emenaker, N.J.; Milner, J.A. Cellular proliferation, apoptosis and angiogenesis: Molecular targets for nutritional preemption of cancer. Semin. Oncol. 2010, 37, 243-257. [CrossRef]

151. Engelman, J.A.; Luo, J.; Cantley, L.C. The evolution of phosphatidylinositol 3-kinases as regulators of growth and metabolism. Nat. Rev. Genet. 2006, 7, 606-619. [CrossRef]

152. Guo, H.; German, P.; Bai, S.; Barnes, S.; Guo, W.; Qi, X.; Ding, Z. The PI3K/AKT Pathway and Renal Cell Carcinoma. J. Genet. Genom. 2015, 42, 343-353. [CrossRef]

153. Hennessy, B.T.; Smith, D.L.; Ram, P.T.; Lu, Y.; Mills, G.B. Exploiting the PI3K/AKT pathway for cancer drug discovery. Nat. Rev. Drug Discov. 2005, 4, 988-1004. [CrossRef]

154. Yang, J.; Nie, J.; Ma, X.; Wei, Y.; Peng, Y.; Wei, X. Targeting PI3K in cancer: Mechanisms and advances in clinical trials. Mol. Cancer 2019, 18, 26. [CrossRef]

155. Alshatwi, A.A.; Ramesh, E.; Periasamy, V.S.; Subash-Babu, P. The apoptotic effect of hesperetin on human cervical cancer cells is mediated through cell cycle arrest, death receptor, and mitochondrial pathways. Fundam. Clin Pharm. 2013, 27, 581-592. [CrossRef]

156. Chen, L.; Deng, H.; Cui, H.; Fang, J.; Zuo, Z.; Deng, J.; Zhao, L. Inflammatory responses and inflammation-associated diseases in organs. Oncotarget 2018, 9, 7204-7218. [CrossRef]

157. Oeckinghaus, A.; Ghosh, S. The NF-kappaB family of transcription factors and its regulation. Cold Spring Harb. Perspect Biol. 2009, 1, a000034. [CrossRef]

158. Vallabhapurapu, S.; Karin, M. Regulation and function of NF-kappaB transcription factors in the immune system. Annu. Rev. Immunol. 2009, 27, 693-733. [CrossRef]

159. Liu, T.; Zhang, L.; Joo, D.; Sun, S.C. NF-kappaB signaling in inflammation. Signal. Transduct Target 2017, 2, 1-9.

160. Chaturvedi, M.M.; Sung, B.; Yadav, V.R.; Kannappan, R.; Aggarwal, B.B. NF-kappaB addiction and its role in cancer: 'one size does not fit all. Oncogene 2011, 30, 1615-1630. [CrossRef]

161. Li, G.; Ding, K.; Qiao, Y.; Zhang, L.; Zheng, L.; Pan, T.; Zhang, L. Flavonoids Regulate Inflammation and Oxidative Stress in Cancer. Molecules 2020, 25, 5628. [CrossRef]

162. Samec, M.; Liskova, A.; Koklesova, L.; Samuel, S.M.; Murin, R.; Zubor, P.; Kubatka, P. The role of plant-derived natural substances as immunomodulatory agents in carcinogenesis. J. Cancer Res. Clin Oncol. 2020, 146, 3137-3154. [CrossRef]

163. Li, H.; Chen, C. Quercetin Has Antimetastatic Effects on Gastric Cancer Cells via the Interruption of uPA/uPAR Function by Modulating NF-kappab, PKC-delta, ERK1/2, and AMPKalpha. Integr. Cancer 2018, 17, 511-523. [CrossRef]

164. Zhou, P.; Wang, C.; Hu, Z.; Chen, W.; Qi, W.; Li, A. Genistein induces apoptosis of colon cancer cells by reversal of epithelial-tomesenchymal via a Notch1/NF-kappaB/slug/E-cadherin pathway. BMC Cancer 2017, 17, 813. [CrossRef]

165. Xia, Y.; Lian, S.; Khoi, P.N.; Yoon, H.J.; Han, J.Y.; Chay, K.O.; Jung, Y.D. Chrysin inhibits cell invasion by inhibition of Recepteur d'origine Nantais via suppressing early growth response-1 and NF-kappaB transcription factor activities in gastric cancer cells. Int. J. Oncol. 2015, 46, 1835-1843. [CrossRef]

166. Krakhmal, N.V.; Zavyalova, M.V.; Denisov, E.V.; Vtorushin, S.V.; Perelmuter, V.M. Cancer Invasion: Patterns and Mechanisms. Acta. Nat. 2015, 7, 17-28. [CrossRef]

167. Fares, J.; Fares, M.Y.; Khachfe, H.H.; Salhab, H.A.; Fares, Y. Molecular principles of metastasis: A hallmark of cancer revisited. Signal. Transduct Target 2020, 5, 28. [CrossRef] 
168. Martin, T.A.; Jiang, W.G. Loss of tight junction barrier function and its role in cancer metastasis. Biochim. Biophys Acta. 2009, 1788, 872-891. [CrossRef]

169. Hsu, M.Y.; Meier, F.E.; Nesbit, M.; Hsu, J.Y.; Van Belle, P.; Elder, D.E.; Herlyn, M. E-cadherin expression in melanoma cells restores keratinocyte-mediated growth control and down-regulates expression of invasion-related adhesion receptors. Am. J. Pathol. 2000, 156, 1515-1525. [CrossRef]

170. Gheldof, A.; Berx, G. Cadherins and epithelial-to-mesenchymal transition. Prog. Mol. Biol. Transl. Sci. 2013, 116, $317-336$.

171. Zhang, X.; Zhang, W.; Chen, F.; Lu, Z. Combined effect of chrysin and apigenin on inhibiting the development and progression of colorectal cancer by suppressing the activity of P38-MAPK/AKT pathway. IUBMB Life 2021, 73, 774-783. [CrossRef]

172. Zang, M.D.; Hu, L.; Fan, Z.Y.; Wang, H.X.; Zhu, Z.L.; Cao, S.; Liu, B.Y. Luteolin suppresses gastric cancer progression by reversing epithelial-mesenchymal transition via suppression of the Notch signaling pathway. J. Transl. Med. 2017, 15, 52. [CrossRef] [PubMed]

173. Liu, H.; Dong, Y.; Gao, Y.; Du, Z.; Wang, Y.; Cheng, P.; Huang, H. The Fascinating Effects of Baicalein on Cancer: A Review. Int. J. Mol. Sci. 2016, 17, 1681. [CrossRef] [PubMed]

174. Aklilu, M.; Kindler, H.L.; Donehower, R.C.; Mani, S.; Vokes, E.E. Phase II study of flavopiridol in patients with advanced colorectal cancer. Ann. Oncol. 2003, 14, 1270-1273. [CrossRef] [PubMed]

175. Miller, K.D.; Siegel, R.L.; Lin, C.C.; Mariotto, A.B.; Kramer, J.L.; Rowland, J.H.; Stein, K.D.; Alteri, R.; Jemal, A. Cancer treatment and survivorship statistics, 2016. CA Cancer, J. Clin. 2016, 66, 271-289. [CrossRef]

176. Ahmad, S.S.; Reinius, M.A.; Hatcher, H.M.; Ajithkumar, T.V. Anticancer chemotherapy in teenagers and young adults: Managing long term side effects. BMJ 2016, 354, i4567. [CrossRef]

177. Okubo, R.; Kinoshita, T.; Katsumata, N.; Uezono, Y.; Xiao, J.; Matsuoka, Y.J. Impact of chemotherapy on the association between fear of cancer recurrence and the gut microbiota in breast cancer survivors. Brain Behav. Immun. 2020, 85, 186-191. [CrossRef]

178. Ichim, T.E.; Kesari, S.; Shafer, K. Protection from chemotherapy-and antibiotic-mediated dysbiosis of the gut microbiota by a probiotic with digestive enzymes supplement. Oncotarget 2018, 9, 30919-30935. [CrossRef]

179. Li, Q.; Ren, L.; Zhang, Y.; Gu, Z.; Tan, Q.; Zhang, T.; Chen, S. P38 Signal Transduction Pathway Has More Cofactors on Apoptosis of SGC-7901 Gastric Cancer Cells Induced by Combination of Rutin and Oxaliplatin. Biomed Res. Int. 2019, $2019,6407210$. [CrossRef]

180. Chen, D.; Wu, J.; Jin, D.; Wang, B.; Cao, H. Fecal microbiota transplantation in cancer management: Current status and perspectives. Int. J. Cancer. 2019, 145, 2021-2031. [CrossRef]

181. Rosshart, S.P.; Vassallo, B.G.; Angeletti, D.; Hutchinson, D.S.; Morgan, A.P.; Takeda, K.; Rehermann, B. Wild Mouse Gut Microbiota Promotes Host Fitness and Improves Disease Resistance. Cell 2017, 171, 1015-1028. [CrossRef]

182. Shetty, S.A.; Marathe, N.P.; Shouche, Y.S. Opportunities and challenges for gut microbiome studies in the Indian population. Microbiome 2013, 1. [CrossRef] 